\title{
Signaling pathways and mesenchymal transition in pediatric high-grade glioma
}

\author{
Michaël H. Meel ${ }^{1}(1)$. Sophie A. Schaper ${ }^{1} \cdot$ Gertjan J. L. Kaspers $^{1,2} \cdot$ Esther Hulleman $^{1}$ (1)
}

Received: 28 August 2017 / Revised: 24 October 2017 / Accepted: 14 November 2017 / Published online: 21 November 2017

(C) The Author(s) 2017. This article is an open access publication

\begin{abstract}
Pediatric high-grade gliomas (pHGG), including diffuse intrinsic pontine gliomas (DIPG), are the most lethal types of cancer in children. In recent years, it has become evident that these tumors are driven by epigenetic events, mainly mutations involving genes encoding Histone 3, setting them apart from their adult counterparts. These tumors are exceptionally resistant to chemotherapy and respond only temporarily to radiotherapy. Moreover, their delicate location and diffuse growth pattern make complete surgical resection impossible. In many other forms of cancer, chemo- and radioresistance, in combination with a diffuse, invasive phenotype, are associated with a transcriptional program termed the epithelial-to-mesenchymal transition (EMT). Activation of this program allows cancer cells to survive individually, invade surrounding tissues and metastasize. It also enables them to survive exposure to cytotoxic therapy, including chemotherapeutic drugs and radiation. We here suggest that EMT plays an important, yet poorly understood role in the biology and therapy resistance of pHGG and DIPG. This review summarizes the current knowledge on the major signal transduction pathways and transcription factors involved in the epithelial-to-mesenchymal transition in cancer in general and in pediatric HGG and DIPG in particular. Despite the fact that the mesenchymal transition has not yet been specifically studied in pHGG and DIPG, activation of pathways and high levels of transcription factors involved in EMT have been described. We conclude that the mesenchymal transition is likely to be an important element of the biology of pHGG and DIPG and warrants further investigation for the development of novel therapeutics.
\end{abstract}

Keywords High-grade glioma · Diffuse intrinsic pontine glioma $\cdot$ Epithelial-to-mesenchymal transition · Glioblastoma Chemoresistance $\cdot$ Radioresistance

\section{Introduction}

Brain tumor is the number one cause of cancer-related morbidity and mortality in children and adolescents. Among pediatric brain tumors, high-grade gliomas (HGG), and especially, diffuse intrinsic pontine gliomas (DIPG) carry the worst prognosis with a 5-year survival of less than $10 \%$ [1]. For DIPG, median survival is only 11 months [2]. On a molecular level, DIPG is characterized by a high prevalence

Esther Hulleman

e.hulleman@vumc.nl

1 Departments of Pediatric Oncology/Hematology, Neuro-oncology Research Group, Cancer Center Amsterdam, VU University Medical Center, De Boelelaan 1117, 1081HV Amsterdam, The Netherlands

2 Princess Máxima Center for Pediatric Oncology, Uppsalalaan 8, 3584CT Utrecht, The Netherlands of mutations in genes encoding Histone 3 (mainly $H 3 F 3 A$ and HISTIH3B), leading to a lysine-to-methionine substitution at position 27 in the $\mathrm{N}$-terminal tail of the histone protein, causing global H3K27 hypomethylation. Supratentorial pHGG often carry a G34R/V mutation in $H 3 F 3 A$, resulting in decreased H3K36 methylation [3-7]. These mutations set the pediatric brain tumors apart from their adult counterparts, and emphasize the necessity to research them independently. Given the highly infiltrative nature and delicate location of DIPG in the brainstem, surgery is generally impossible. Historically, the diagnosis of DIPG was based on MRI appearance of the tumor, and surgical biopsies were rarely performed. However, in recent years, many institutes are re-introducing biopsies in early clinical phase studies to enable molecular characterization of the tumor [8]. In contrast, supratentorial pHGG is almost always subjected to surgery. Although rarely resulting in a cure of the patient, the extent of surgical resection is one of the most important 
independent clinical prognostic factors [9]. Additionally, pediatric HGG and DIPG are extremely chemoresistant, partially due to the blood-brain barrier (BBB) and partially due to intrinsic factors [10]. To this day, no chemotherapy regimen is known to produce any response in DIPG at acceptable toxicity levels, and only a very modest survival benefit of chemotherapy is seen in supratentorial pediatric HGG [9]. The only treatment that definitively benefits patients with pHGG and DIPG is intensive radiotherapy, which alleviates symptoms and slightly prolongs survival, but offers no chance for a cure. In adult glioblastoma (GBM), as in other types of cancer, the intrinsic chemoresistance has been related to the process of epithelial-to-mesenchymal transition (EMT), a transcriptional process in which epithelial cells adopt mesenchymal properties by loss of cell-cell adhesion, acquisition of migratory and invasive properties and loss of cell polarity [11, 12]. In tumors, in general, EMT contributes to initiation, invasion, metastasis to distant sites and resistance to chemo- and/or radiotherapy. Additionally, it is believed to stimulate the development and maintenance of a cancer stem cell (CSC) population within the tumor [13-15]. We hypothesize that EMT plays an equally important role in pediatric HGG and DIPG, by which it would be responsible for the intrinsic chemoresistance and diffuse nature of these tumors.

EMT is induced by external factors, such as cytokines, growth factors and hypoxia. Different signaling pathways lead to activation of EMT transcription factors; most importantly SNAI1 (SNAIL), SNAI2 (SLUG), ZEB1, ZEB2 and TWIST. These transcription factors inhibit the expression of genes that promote cell-cell contact, most importantly E-cadherin, and induce genes that promote migration and stemness [11, 16-18]. This review serves to summarize current knowledge on the process of mesenchymal transition in pediatric HGG and DIPG.

\section{Transcription factors involved in the mesenchymal transition}

\section{SNAIL family of transcription factors}

One of the most important regulators of the mesenchymal transition is the SNAIL family of master transcriptional regulators, consisting of three members; SNAIL (SNAI1), SLUG (SNAI2) and SMUC (SNAI3). SNAIL family transcription factors are basic zinc finger transcription factors with a broad variety of functions during normal development and cancer progression [19-22]. Most research has been dedicated to unraveling the role of these factors in the epithelial-to-mesenchymal transition. Central to this role is their ability to repress E-cadherin transcription through direct binding to the $\mathrm{CDHI}$ promoter and concurrently increase the expression of other cadherins, such as N-cadherin (CDH2) [11, 23]. Furthermore, SNAIL transcription factors have a profound impact on epigenetic regulation of transcription through recruitment of several histone methyltransferases, demethylases, acetyltransferases and deacetylases to the histone-DNA complex, thus resulting in the transcription of genes associated with a mesenchymal phenotype and concurrent repression of epithelial genes, such as occludins, claudins, mucins and cytokeratins [24, 25] (Fig. 1).

Among the most important mesenchymal proteins are vimentin, fibronectin and matrix metalloproteinases [19]. These proteins are involved in the structural integrity of mesenchymal cells, both through integrin signaling and their capacity to modify the extracellular environment [26, 27]. In cancer progression, this expression of mesenchymal genes [28] allows cancer cells to become less dependent of cell-cell interactions, enabling them to migrate, invade surrounding tissues and eventually metastasize [20, 29-32]. Additionally, SNAIL upregulates the expression of ZEB1, another master transcriptional regulator of the mesenchymal transition [33]. Finally, an important role for these transcription factors lies in their ability to render cancer cells resistant to therapy via incompletely understood mechanisms, as is the case for example in cisplatin-resistant NSCLC, and especially relevant for the current review, $\operatorname{GBM}[12,19,20]$. Importantly, SNAIL is found to be a key player in mesenchymal transition in malignant gliomas, including DIPG, increasing invasion migration, focal adhesion and proliferation [34-38]. SNAIL levels increase after irradiation [34] and its expression is correlated with tumor grade and survival [39]. Although SLUG is not as extensively studied in gliomas as SNAIL, it too is correlated with invasion, histological grade and glioblastoma growth [40].

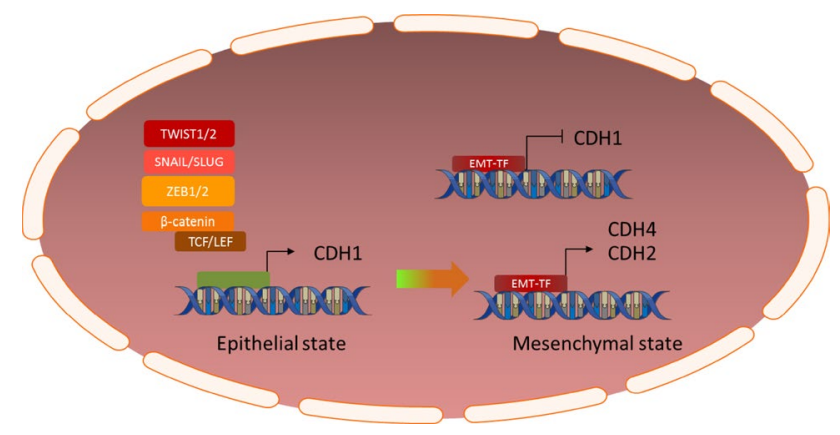

Fig. 1 Graphic illustration of the cadherin switch; EMT transcription factors inhibit expression of E-Cadherin (CDH1) and induce expression of $\mathrm{N}$ - and/or R-Cadherin, a crucial event in the (epithelial-to-) mesenchymal transition 


\section{ZEB family of transcription factors}

Another group of master regulators of the mesenchymal transition is the ZEB family of transcription factors, comprising ZEB1 and ZEB2. These transcription factors contain two zinc finger domains which allow DNA binding at E-boxes within the promoter regions of target genes such as E-cadherin and N-cadherin [11]. Whether ZEB1 and ZEB2 function as transcriptional activators or repressors is determined by their interaction with cofactors, such as the Smad family of signal transduction proteins, and other transcription factors. The net result of ZEB activity, however, is always a skewing of gene expression to a more mesenchymal phenotype [41]. Overexpression of ZEB1 and ZEB2 is a common phenomenon in many types of cancer, where it is associated with the maintenance of a cancer stem cell phenotype as well as metastasis and therapy resistance, such as paclitaxel resistance in breast cancer cells [42-44].

ZEB1 has been found to be correlated to a highly infiltrative tumor phenotype in both adult and pediatric high-grade glioma, partially in relation to hypoxia $[45,46]$. Moreover, ZEB1 expression is linked to poor temozolomide response and a shorter survival of GBM patients [45]. Interestingly, ZEB1 has been shown to be important for EMT in HGG driven by PDGFR $\alpha$ activation [47]. As pediatric HGG commonly possesses PDGFR $\alpha$ overexpression and activation, this ZEB1-PDGFR $\alpha$ axis may well be important for the mesenchymal transition of pHGG [38, 48-50]. Although less well studied, ZEB2 expression also appears to be correlated with tumor grade and mesenchymal properties in high-grade gliomas [51]. Specific data on the role of ZEB2 in pediatric HGG and DIPG is lacking.

\section{TWIST family of transcription factors}

A third group of master regulators of the mesenchymal transition is the TWIST family of basic helix-loop-helix (bHLH) transcription factors, of which TWIST1 and TWIST2 have been studied most. Basic HLH transcription factors, such as the zinc finger transcription factors, exert their action through binding to the E-boxes in the promotor regions of target genes. In this manner, as with the SNAIL and ZEB families of transcription factors, TWIST represses E-cadherin and enhances $\mathrm{N}$-cadherin expression, thereby promoting tumor cell migration, invasion, metastasis and chemoresistance in a broad variety of cancer types [52-55].

TWIST1 has been repeatedly investigated in adult glioma, in which its expression is correlated with higher tumor grade and poorer survival of patients. Mechanistically, this is attributed to the increased migratory and invasive capacities of glioma cells by TWIST1 activity [56]. Additionally, TWIST1 expression has been associated with resistance of glioblastoma cells to temozolomide [57]. Importantly, one study found that a reduction of TWIST1 expression in glioma stem cells, achieved by co-culturing these stem cells with mesenchymal stem cells, induces a mesenchymal-toepithelial transition (MET), the inverse process of EMT, in these cells [58]. Specific data on the role of TWIST in pediatric HGG and DIPG is not available.

\section{SIX family of transcription factors}

Less well studied, but nonetheless relevant, is the SIX family of homeobox transcription factors, of which only SIX1 has received considerable attention. These transcription factors are highly expressed in embryogenesis, where they have an important role in embryonal progenitor cell proliferation and survival. When SIX proteins are aberrantly expressed in non-embryonal tissue they can function as oncogenes, promoting cell proliferation and metastasis in various cancer types, partially through activation of the TGF- $\beta$ and RAS/ MAPK pathways [59-63].

SIX1 has mostly been studied in breast cancer, where it correlates with worse patient survival and induces EMT in cancer stem cells, thereby causing malignant progression $[61,64]$. Furthermore, SIX1 has been shown to play a role in EMT in high-grade glioma cells, resulting in increased cell invasiveness $[65,66]$. To date, no research has addressed the role of the SIX transcription factors in pediatric HGG or DIPG.

\section{External initiation of the epithelial-to-mesenchymal transition}

The epithelial-to-mesenchymal transition is commonly initiated by external stimuli, such as growth factors, cytokines and/or hypoxia. These external stimuli trigger intracellular signaling cascades that ultimately result in an upregulation of transcriptional regulators, such as SNAIL and ZEB [11]. Key pathways in this process include TGF $\beta$ and activin signaling, WNT signaling, JAK/STAT, RTK and SHH signaling (Fig. 2).

\section{TGF- $\beta$ and activin signaling}

One of the first mechanisms discovered by which external triggers could induce EMT is the TGF- $\beta$ signaling pathway. The TGF- $\beta$ superfamily consists of two activins, three TGF- $\beta$ s and many bone morphogenetic proteins that all function through homo- or heterodimers of receptors. Binding of TGF- $\beta$ or related proteins to their receptors causes phosphorylation of tyrosine, serine and/or threonine residues in the cytoplasmic domain of the receptor. Via a series of intermediate events, this results in phosphorylation of SMAD2 and SMAD3, which in turn form a complex with 
Fig. 2 Graphic illustration of signaling pathways conveying external signals to transcription of mesenchymal genes, thereby initiating and maintaining the (epithelial-to-)mesenchymal transition

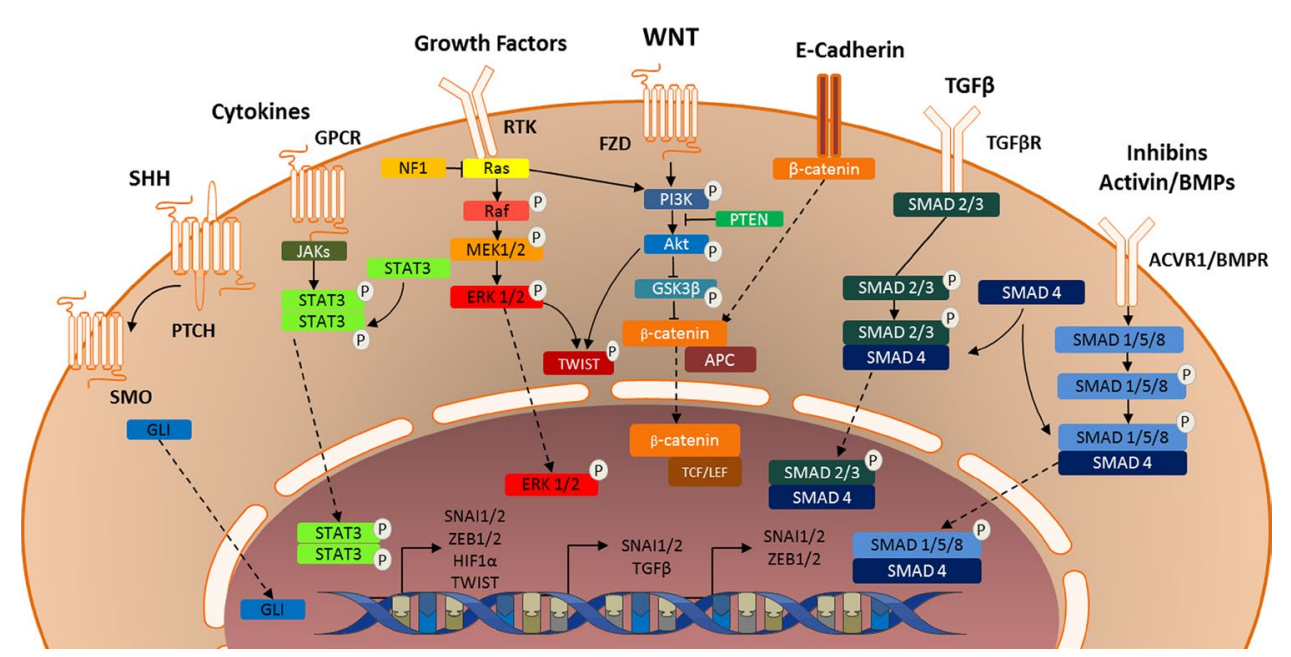

and phosphorylate SMAD4 [11, 67] (Fig. 2). This trimeric complex translocates to the nucleus, where it both causes expression of and interacts with transcription factors capable of inducing EMT, such as SNAIL, SLUG, ZEB1 and ZEB2 [11]. Furthermore, activation of TGF- $\beta$ receptors by their ligands can activate canonical signaling pathways such as the $\mathrm{PI}_{3} \mathrm{~K} / \mathrm{AKT}$, MAPK and JNK pathways, which will be discussed later on $[68,69]$.

In pediatric high-grade glioma, a special role seems to be reserved for the activins within the TGF- $\beta$ superfamily of proteins. Recent studies have identified activating mutations gene encoding Activin Receptor Type 1 (ACVRI) in a subset of diffuse midline gliomas [50, 70,71]. Mutations in this gene are known to cause ligand-independent receptor activation with subsequent phosphorylation and nuclear translocation of SMAD1, SMAD 5 and SMAD8 [70, 72-74]. There, they too form a complex with SMAD4 to function as a transcription factor regulating expression of genes inducing EMT [74]. As with many proteins involved in EMT, ACVR1 seems to be mainly involved in embryogenesis under normal circumstances [73]. This observation raises the possibility that ACVR1 mutations induce the mesenchymal transition in diffuse midline gliomas. This hypothesis is supported by the observation that ACVR1 mutations are associated with a mesenchymal gene expression profile in diffuse intrinsic pontine glioma [38]. This makes both ACVR1 and its downstream effectors interesting targets for the treatment of diffuse intrinsic pontine gliomas, especially when combined with other therapeutic modalities.

\section{WNT signaling in the mesenchymal transition}

In the canonical WNT/ $\beta$-catenin pathway, WNT first binds to Frizzled cell surface receptors and low-density lipoprotein-related receptor proteins 5 or 6 [75-78]. The activation of Frizzled receptors results in phosphorylation of AKT, followed by inhibitory phosphorylation of GSK3 $\beta$, resulting in stabilization of SNAIL protein [11]. Moreover, GSK3 $\beta$ inhibition enables $\beta$-catenin to act as a transcription factor. Normally, GSK $3 \beta$ is part of a complex with the proteins APC and AXIN, the so-called destruction complex. This complex phosphorylates and thereby degrades $\beta$-catenin [79, 80]. Therefore, when GSK $3 \beta$ is inhibited, $\beta$-catenin accumulates in the cytoplasma and translocates to the nucleus [81, 82]. There, it serves as a subunit of a high-mobility group (HMG) box transcription factor complex. In association with TCF/LEF, $\beta$-catenin induces the expression of genes encoding EMT transcription factors $[83,84]$. In addition, $\beta$-catenin is an important part of the E-cadherin/ $\beta$-catenin complex that regulates cellular adhesion and migration, making the WNT/ $\beta$-catenin pathway a key mechanism regulating EMT in cancer (stem) cells [13].

The WNT/ $\beta$-catenin pathway has many interactions with other pathways involved in EMT. For example, it cooperates with TGF- $\beta$ signaling to induce EMT in palate medial-edge epithelial cells $[11,85]$ and increases HIF- $1 \alpha$ expression in prostate and liver cancer, which in turn results in EMT [86-90]. In glioma there is ample evidence for the relevance of the WNT/ $\beta$-catenin pathway in the mesenchymal transition. First, expression of pathway components correlates to survival in glioma patients [91-93]. Second, WNT/ $\beta$-catenin signaling has been shown to promote glioma cell proliferation, migration, invasion and radio- and chemoresistance [94-104]. Most importantly, however, EMT-mediated chemoresistance can be reversed in glioblastoma stem cells by treatment with secreted Frizzled-related protein (sFRP4), which functions as a WNT antagonist $[105,106]$. A recent study demonstrated that the role of WNT/ $\beta$-catenin signaling in pediatric HGG, in contrast to adult GBM, is very limited [107].

Besides the canonical WNT/ $\beta$-catenin pathway, two noncanonical WNT signaling pathways have been identified; the planar cell polarity (PCP) and $\mathrm{WNT} / \mathrm{Ca}^{2+}$ pathways $[108$, 109]. Although not extensively studied, components of these 
pathways, most importantly WNT5A, have been shown to be involved in the induction of EMT in several types of cancer [110-114]. Both non-canonical WNT pathways have been shown to play a role in adult glioma, where they increase stemness and invasive properties of glioma cells [109, 115-122]. Data on the role of non-canonical WNT signaling in pHGG and DIPG has not been published to this day.

\section{$\mathrm{Pl}_{3} \mathrm{~K} / \mathrm{AKT}$ signaling in the mesenchymal transition}

Activation of well-known receptor tyrosine kinases (RTK), such as the EGF, FGF and PDGF receptors, as well as G-protein coupled receptors (GPCR), is known to induce EMT via activation of the canonical $\mathrm{PI}_{3} \mathrm{~K} / \mathrm{AKT}$ and RAS/ MAPK pathways. The role of the $\mathrm{PI}_{3} \mathrm{~K} / \mathrm{AKT}$ pathway in EMT is well established; after activation of the pathway, AKT inhibits GSK3 $\beta$ by phosphorylating serine 9 . This in turn prevents GSK3 $\beta$ from phosphorylating SNAIL or SLUG, thus inhibiting their ubiquitination and subsequent proteasomal degradation [123, 124]. Via this mechanism, activation of the $\mathrm{PI}_{3} \mathrm{~K} / \mathrm{AKT}$ pathway causes stabilization of SNAIL family proteins, thereby inducing EMT [11].

In addition, activation of the $\mathrm{PI}_{3} \mathrm{~K} / \mathrm{AKT}$ pathway induces the transcription of ZEB1 by reducing GSK3 $\beta$-mediated phosphorylation of $\beta$-catenin, thereby stabilizing the protein and inducing $Z E B 1$ transcription via a $\beta$-catenin/TCF4 complex [125, 126]. Finally, AKT-mediated TWIST1 phosphorylation promotes EMT, as for example in the case of breast cancer metastasis, by modulating its transcriptional target TGF- $\beta 2$, leading to enhanced TGF- $\beta$ receptor signaling. This signaling pathway in turn maintains hyperactive phosphoinositide 3-kinase $\left(\mathrm{PI}_{3} \mathrm{~K}\right) / \mathrm{AKT}$ signaling), resulting in induction of EMT [127]. The $\mathrm{PI}_{3} \mathrm{~K} / \mathrm{AKT}$ pathway, which is commonly activated in malignant cells, has been shown to induce EMT in several tumor types. In certain types of cancer, inhibition of the overactive $\mathrm{PI}_{3} \mathrm{~K} / \mathrm{AKT}$ signaling resulted in a decrease of mesenchymal characteristics and (re-)sensitization of cancer cells to chemo- and radiotherapy [128-131].

There are several EMT pathways that cross talk with the $\mathrm{PI}_{3} \mathrm{~K} / \mathrm{AKT} / \mathrm{GSK} 3 \beta$ pathway in glioma, for example the HIF- $1 \alpha$ and the WNT/ $\beta$-catenin pathways [132-135]. Moreover, loss of PTEN is often found in adult GBM, leading to aberrant activation of the $\mathrm{PI}_{3} \mathrm{~K}$ pathway [136]. In line with this finding, $\mathrm{PI}_{3} \mathrm{~K} / \mathrm{mTOR}$ kinase inhibitors provide a promising glioma therapy, as those drugs sensitize tumor cells to radiation and chemotherapy [137]. In pediatric HGG and DIPG, activating mutations in genes encoding $\mathrm{PI}_{3} \mathrm{~K}$ are found in 15-26\% of patients [138-140], which may contribute to the mesenchymal transition in these tumors.
RAS/MAPK signaling in the mesenchymal transition

Activation of RTKs also leads to signaling via the RAS/ MAPK pathway [141]. Within this cascade, ERK1/2 phosphorylation and subsequent nuclear translocation leads to an increase in the transcription of SNAIL and $S L U G$ and regulators of cell invasion and motility through activation of RHO-GTPases [11, 142]. Additionally, MAPK signaling leads to increased phosphorylation and stabilization of TWIST1 [143], as well as increased transcription of TGF- $\beta$ $[144,145]$. Oncogenic mutations in the RAS/MAPK pathway, such as loss of NF1, a negative regulator of RAS, or activating mutations in BRAF and KRAS are common in cancer and have been shown to induce EMT [143, 146-151]. In these tumors, treatment with MEK inhibitors resulted in a reduction in EMT-associated proteins and even signs of induction of MET [145, 152-154]. In pediatric low-grade glioma (LGG), activating mutations of BRAF are common, and confer a worse prognosis [155]. In contrast, mutations in the RAS/MAPK pathway are rare in high-grade glioma, although loss of NF1 is sometimes found [136]. Yet, activation of the MAPK pathway is common, because of amplifications or mutations in EGFR and other RTKs [156]. In pediatric HGG, mutations in the RAS/MAPK pathway and loss of NF1 are even less frequent, compared to the adult disease with the lowest prevalence found in DIPG [138-140, 157]. Additionally, activating EGFR mutations are not found in pediatric HGG, although amplification of the EGFR and PDGFRA genes has been described [38, 49, 50, 139]. The significance of these findings in pediatric $\mathrm{HGG}$ is unclear; trials with MEK inhibitors in pediatric HGG and LGG give promising results [158], whereas a trial using the multikinase inhibitor sorafenib in pediatric low-grade glioma patients resulted in paradoxical progression of BRAF wild type tumors [159].

\section{The TAM family of receptor tyrosine kinases}

Among the receptor tyrosine kinases, the TAM family, consisting of TYRO3, AXL and MERTK, plays a particular role in the induction of EMT. TYRO3 and MERTK can both be activated by binding of their endogenous ligands protein S and Gas6, whereas AXL can only bind Gas6 [160]. Additionally, AXL can form heterodimers with other RTKs, such as the EGF and PDGF receptors, thereby being transactivated by binding of their respective ligands [161]. Activation of TAM receptors triggers intracellular signaling cascades that have resulted in EMT in a large number of cancer types. Consequently, TAM signaling has been proven to be involved in migration of cancer cells in hepatocellular, colorectal and breast cancer, and resistance to chemo- and targeted therapy in breast cancer [161-173]. 
In glioblastoma, both AXL and MERTK have been identified as potential therapeutic targets and causes of treatment resistance. Inhibition of AXL and/or MERTK leads to diminished proliferation, migration and invasion of glioma cells, as well as sensitization of glioma cells to chemotherapy [174-180] Although specific studies addressing the biological role of the TAM RTKs in pediatric HGG and DIPG are not available, overexpression of both AXL and MERTK has been described, and AXL has been shown to be activated in cultured DIPG cells [180, 181].

\section{The JAK/STAT pathway in the mesenchymal transition}

Besides the $\mathrm{PI}_{3} \mathrm{~K} / \mathrm{AKT}$ and RAS/MAPK pathway, a third pathway can be activated after engagement of cell surface receptors by their ligands; the JAK/STAT pathway. Although commonly associated with GPCRs, RTKs are also capable of initiating signaling along the JAK/STAT pathway. In this pathway, receptor-associated Janus kinases (JAKs) phosphorylate and activate signal transducer and activator of transcription (STAT) proteins. Upon phosphorylation, STATs form homo- or heterodimers that can function as transcription factors [182]. Within this family of proteins, STAT3 is known to induce EMT through upregulating the transcription of SNAIL1, ZEB1, HIF-1 $\alpha$, and most importantly, TWIST [183-187]. Under normal circumstances, activity of the JAK/STAT3/TWIST pathway is involved in neurogenesis and astrogliogenesis [188]. In cancer, however, aberrant activation of the pathway can induce EMT and thereby chemoresistance, as has been described, for example, in colorectal [184], breast [183] and ovarian cancer [189]. Based on these findings, clinical trials utilizing STAT3 inhibitors are currently ongoing for breast cancer [190, 191], ovarian cancer [189] and bile duct cancer [192]. In adult glioma, STAT3 activation is associated with increased tumor growth, angiogenesis, therapy resistance and worse patient outcome [12]. STAT3 activation enhances glioma stem cell self-renewal, as well as invasion and migration of glioma cells. Furthermore, inhibition of STAT3 enhances the response of glioma cells to temozolomide and radiation [193-196]. This suggests that inhibiting the JAK/STAT3 pathway may be an effective therapeutic strategy for high-grade glioma. The same might be true for pediatric HGG and DIPG, as overexpression of STAT3 has been reported as one of the hallmarks of the mesenchymal subtype in these tumors [38]. Additionally, overexpression of interleukin- 4 and -13 receptors, known to induce JAK/STAT signaling, has been described in pediatric high-grade gliomas and DIPG [197-200].

\section{The sonic hedgehog pathway in the mesenchymal transition}

Sonic hedgehog $(\mathrm{SHH})$ is a soluble glycoprotein that can bind to the transmembrane receptor Patched1 (PTCH1), thereby inducing phosphorylation and stabilization of another transmembrane receptor, Smoothened (SMO). Activated SMO phosphorylates a variety of intracellular signaling molecules that eventually lead to increased activity of the GLI family of transcription factors [201, 202]. The GLI proteins, in turn, induce the expression of genes associated with EMT, such as SNAI1, SNAI2, ZEB1, ZEB2 and TWIST [203, 204]. In the signaling cascade following activation of Smoothened there is a large amount of crosstalk with other pathways involved in EMT, such as the NOTCH, WNT/ $\beta$ catenin, TGF- $\beta$ and EGFR pathways [205, 206]. Aberrant activation of the Hedgehog pathway is involved in EMT in various malignancies, such as breast cancer and gastric cancer [207, 208]. In high-grade glioma cells, it has been shown to be involved in invasion, migration, proliferation and maintenance of stem cell properties [205, 209]. Moreover, high activity of the hedgehog pathway is correlated to worse outcome in patients suffering from HGG [210].

Inhibition of SMO represents a promising strategy to overcome therapy resistance in $\mathrm{HGG}$; the Smoothened inhibitor cyclopamine has been shown to induce radiosensitization in glioblastoma cells and Erismodegib, another SMO inhibitor, was capable of inhibiting self-renewal and EMT in glioblastoma initiating cells [211, 212]. Additionally, chemical inhibition of the hedgehog pathway could sensitize glioma stem cells to temozolomide [213].

The hedgehog pathway has been found to be active in DIPG cells, where it plays a crucial role in self-renewal of malignant cells [214]. Its connection with the mesenchymal transition described in DIPG has not been studied yet.

\section{The NOTCH pathway in the mesenchymal transition}

Mammalian cells express four transmembrane NOTCH receptors, NOTCH 1-4, and five canonical transmembrane ligands: Delta-like 1, Delta- like 3, Delta- like 4, Jagged-1 and Jagged-2. [215] When a NOTCH ligand binds to two adjacent NOTCH receptors of neighboring cells, NOTCH will be cleaved into an extracellular and an intracellular domain, by a dysintegrin and metalloproteinase domaincontaining protein (ADAM) 10 or ADAM 17 and $y$-secretase (Fig. 3). The active intracellular domain of NOTCH translocates to the nucleus, binds to C-protein binding factor 1/ Suppressor of Hairless/Lag-1 (CSL), forming a transcription activator complex. The NOTCH-CSL complex induces transcription of numerous genes associated with differentiation and/or survival including a variety of genes associated with EMT, such as SNAIL1, SNAIL2, ZEB1, FN1 and PDGFRs 
Fig. 3 Graphic illustration of NOTCH signaling and hypoxia in the induction of the (epithelial-to-)mesenchymal transition

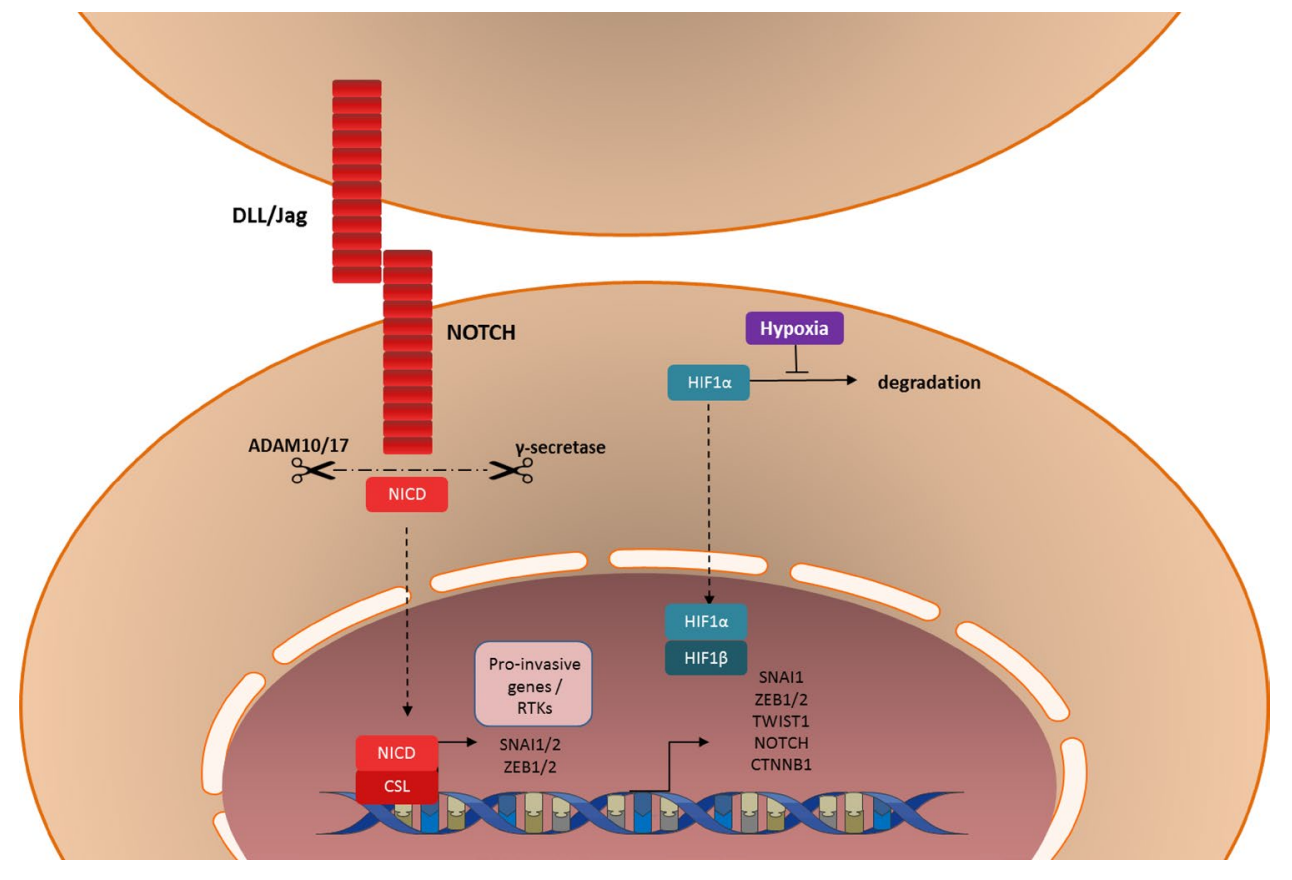

[216-218]. Furthermore, there is evidence of extensive crosstalk between the TGF- $\beta$ and NOTCH pathways in the process of EMT [219, 220]. As with many other factors involved in EMT, the normal function of the NOTCH pathway seems to be in embryonic development and stem cell maintenance [219]. However, the NOTCH pathway is commonly dysregulated in cancer cells, where it can serve as both a tumor suppressor and as an oncogene, dependent on the cancer type [219]. NOTCH signaling induces proliferation, migration and invasion of glioma cells and is required for maintenance of both normal neural stem cells and glioma stem cells [221-224]. In these stem cells, NOTCH signaling induces self-renewal and inhibits differentiation [217, 225, 226]. Consequently, high levels of NOTCH signaling are associated with a poor prognosis in patients suffering from GBM [224]. $\gamma$-Secretase inhibitors have been shown to reduce proliferation and signs of stemness in glioma cells and to sensitize them to chemotherapy and radiation [227-231]. Moreover, these inhibitors have been shown to reduce proliferation of DIPG cells in vitro and to increase their radiosensitivity [232]. Although the role of NOTCH in EMT in pediatric HGG and DIPG has not been addressed yet, these results make it an interesting target for future translational research.

\section{Role of hypoxia in the mesenchymal transition}

Another external factor, other than growth factors and cytokines that is capable of inducing mesenchymal transition is hypoxia. Exposure of tumor cells to hypoxia induces stabilization of hypoxia-inducible factor $1 \alpha(\mathrm{HIF}-1 \alpha)$, which dimerizes with HIF-1 $\beta$ to form a transcription factor complex (Fig. 3). Activity of this complex results in expression of genes involved in EMT, including NOTCH, CTNNB1 ( $\beta$-catenin), SNAIL1 and TWIST [233-239]. Additionally, the expression of HIF-2 $\alpha$ (EPAS1) is associated with ZEB2induced EMT in breast cancer [240].

Besides EMT, these hypoxia-inducible factors induce expression of genes responsible for stem cell properties, such as self-renewal and multipotency via mechanisms common to EMT, such as the NOTCH signaling pathway [241]. Furthermore, in many different cancer types, hypoxia-inducible factors are involved in proliferation, migration and invasion, reinforcing the hypothesis that hypoxia can initiate EMT in cancer cells [235, 237-239, 242, 243]. In glioblastoma cells specifically, hypoxia induces and maintains stem cell characteristics, and HIF-1 $\alpha$ has been shown to be involved in proliferation, migration invasion and radio- and chemoresistance [238, 239, 244-252]. In both adult and pediatric HGG, overexpression of HIF- $2 \alpha$ has been found, which negatively correlated with patient survival [247, 253], although data on $\mathrm{HIF}-1 \alpha$ in pediatric HGG is lacking.

\section{The cadherin switch}

The ultimate result of activation of the EMT-related signaling pathways described above is the so-called cadherin switch [254-257] (Fig. 1). Cadherins are a large family of transmembrane glycoproteins involved in intercellular adhesions and signaling. Epithelial cells normally express E-cadherin, the expression of which is tightly regulated. The 
SNAIL and ZEB families of transcription factors bind to an E-Box motif in the promoter region of the $\mathrm{CDH} 1$ gene, causing its transcriptional repression [11, 23, 41]. Simultaneously, they induce an upregulation of other cadherins, mostly CDH2 and/or CDH4 [11]. Other transcription factors involved in the mesenchymal transition, such as TCF3 (E12/E47), and the TWIST and SIX families of transcription factors, induce similar changes in cadherin expression via different mechanisms than described above [11, 254-257]. Loss of expression of E-cadherin (CDH1), and induction of expression of $\mathrm{N}$ - or R-cadherin $(\mathrm{CDH} 2$ or $\mathrm{CDH} 4)$, triggers a series of events that allows cancer cells to become less dependent of their micro-environment, thereby promoting cell migration, invasion and metastasis [254-257]. Additionally, the intracellular domain of E-cadherin binds $\beta$-catenin(CTNNB1), and loss of its expression causes $\beta$-catenin to locate to the nucleus where it acts as a transcription factor for various genes associated with the mesenchymal phenotype [257, 258]. The broad range of functions attributed to cadherins also includes profound influences on several signal transduction pathways, such as the $\mathrm{PI}_{3} \mathrm{~K} / \mathrm{AKT}$, MAPK and NF-kB pathways, both directly and through modulation of receptor tyrosine kinases such as FGFR, EGFR, PDGFR and integrin-linked kinases [259-263].

In adult glioblastoma (GBM), loss of E-cadherin expression and concurrent increase in either $\mathrm{N}$ - or R-cadherin expression is related to a more mesenchymal phenotype, tumor invasiveness and worse overall survival [254, 260, 264-266]. Furthermore, the mesenchymal phenotype seems to be responsible for an increased resistance to chemotherapy and radiation, two important modalities in GBM treatment [15]. To this date, the role of cadherins in pediatric high-grade glioma has not been sufficiently addressed to determine their precise role in the mesenchymal transition in these tumors.

\section{Discussion}

Over the past years, the mesenchymal transition has received considerable attention in the field of oncology, due to its relationship with invasion, metastasis and therapy resistance of cancer cells. Components of the mesenchymal transition have often been put forward as therapeutic targets and/or therapy-sensitizing agents, not in the least in the treatment of adult glioblastoma. However, little research is available on the role of the mesenchymal transition in pediatric high-grade glioma and diffuse intrinsic pontine glioma. The therapy resistance and diffusely infiltrative nature that these tumors often possess imply that mesenchymal gene expression may play a larger role in their biology than is known so far. We have reviewed current knowledge about the major signal transduction pathways involved in initiation and maintenance of the mesenchymal transition in cancer in general, and high-grade glioma in particular.

When comparing published RNA expression datasets available from normal brain tissue [267], adult GBM [268], pediatric HGG [49] and DIPG [48], major differences can be found in the expression of certain key components of the mesenchymal transition (Fig. 4). Most prominently, expression of the transcription factor ZEB1 is higher in pHGG and DIPG compared to adult GBM, whereas expression of SIX1 is upregulated in both pHGG and adult GBM, but not in DIPG. This is in contrast with other transcription factors, such as TCF3, the expression of which was equal in all three tumor types. Expression of upstream regulators of transcription factors involved in the mesenchymal transition revealed further differences between pHGG, DIPG and adult GBM. Most strikingly, the expression of EGFR and ERBB2-two commonly targeted RTKs in the treatment of glioma-was much higher in adult GBM compared to pHGG and DIPG. Combined with the observation from previous studies that EGFR mutations are rarely to never found in pediatric HGG and DIPG, these data suggest that the role of EGFR signaling in pediatric gliomas is more limited than in the adult counterpart $[38,49,50,139]$. On the contrary, the expression of Patched (PTCH1), an important component of the hedgehog pathway, was higher in DIPG than in supratentorial pHGG and adult GBM, possibly as a result of their different developmental origins [214]. Finally, in contrast to previous reports describing overexpression of HIF2A in both pediatric and adult HGG [247, 253], only adult GBM possessed HIF2A overexpression in the datasets we analyzed, whereas HIF1A was overexpressed in all three tumor types. Tables 1 and 2 present a brief overview of transcription factors and signaling pathways addressed in this review and compare their relative importance in $\mathrm{pHGG}$, DIPG and adult GBM, as far as current knowledge allows for.

The differences in mechanisms of mesenchymal transition employed by pHGG and DIPG as compared to adult GBM will provide researchers with important clues in the identification of therapeutic targets and the design of novel therapeutic strategies to overcome therapy resistance and metastasis in these hard-to-treat brain tumors. With the currently available knowledge, several promising therapeutic targets for interfering with the mesenchymal transition in pHGG and DIPG can already be identified. With the development of selective ACVR1 inhibitors, tumors harbouring activating $A C V R I$ mutations and a mesenchymal phenotype can potentially be chemo- and radio-sensitized using these compounds [269]. Furthermore, tumors possessing a mesenchymal phenotype related to mutations in the $\mathrm{PI}_{3} \mathrm{~K}$ and/ or MAPK pathway can potentially be sensitized to therapy by the use of $\mathrm{PI}_{3} \mathrm{~K}$ or MEK inhibitors, many of which are already clinically approved for other indications. Also, considering the perceived importance of the hedgehog pathway 

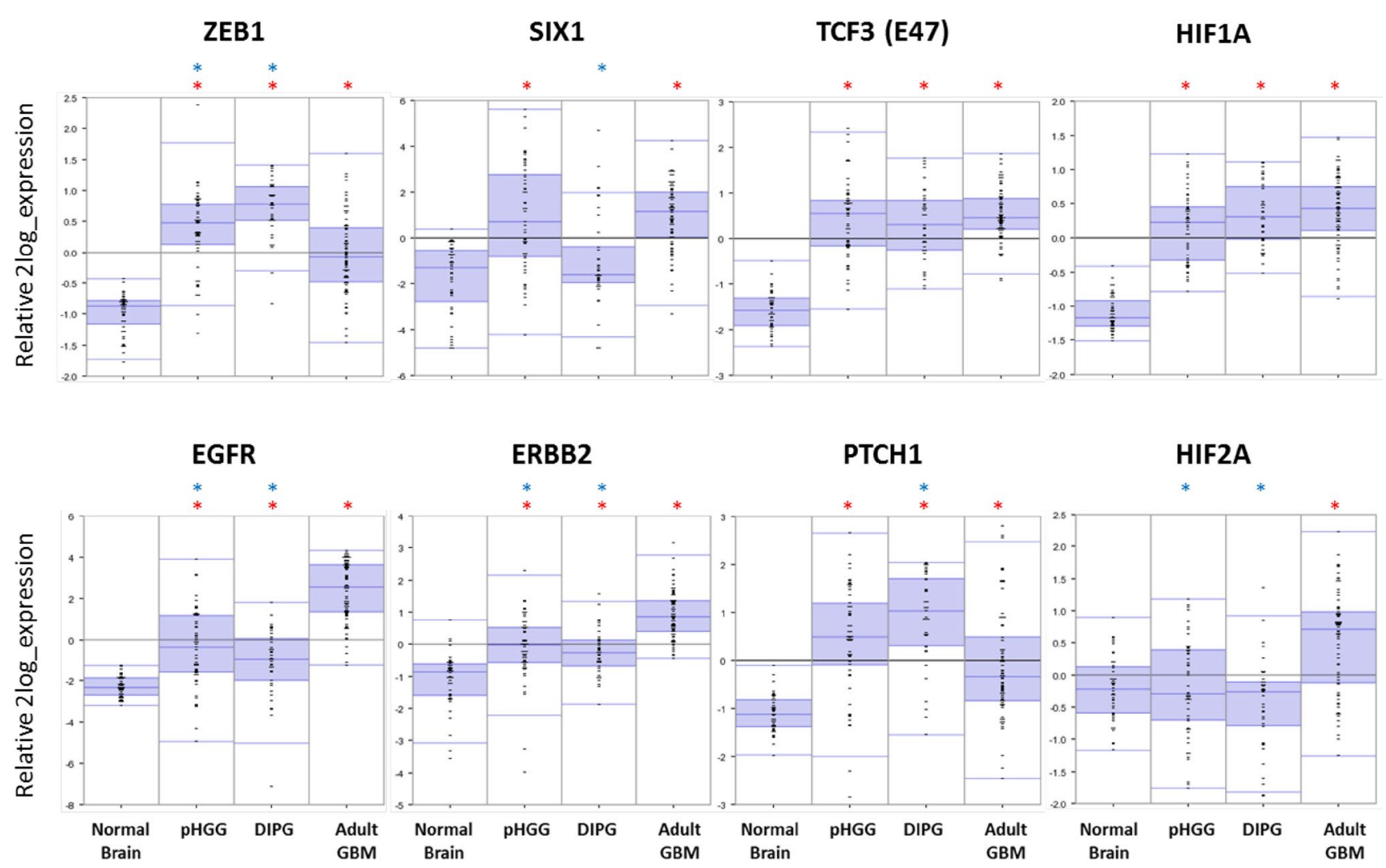

Fig. 4 RNA expression levels of genes involved in the (epithelial-to-) mesenchymal transition that show a strong differential expression between normal brain tissue [267], adult GBM [268], pediatric HGG [49] and DIPG [48]. Source: R2 (http://r2.amc.nl). Blue stars indicate

significant differences $(p<0.01)$ compared to adult GBM, red stars indicate significant differences $(p<0.01)$ compared to normal brain tissue

Table 1 Summary of major transcription factors involved in the mesenchymal transition and their role in adult GBM, pediatric HGG and DIPG

Transcription factors Relevance in adult GBM, pediatric HGG and DIPG

\begin{tabular}{ll}
\hline SNAIL family & $\begin{array}{c}\text { Proven important role in mesenchymal transition in adult GBM, suggested to play a role in DIPG, insufficient data on } \\
\text { pediatric HGG } \\
\text { Proven role in mesenchymal transition in adult GBM and pediatric HGG, insufficient data on DIPG. The presence of a } \\
\text { PDGFR } \alpha \text {-ZEB1 axis and expression levels of ZEB1/2 suggest important role in pediatric HGG and DIPG }\end{array}$ \\
TWIST family & $\begin{array}{l}\text { Proven important role in mesenchymal transition in adult GBM, no available data on pediatric HGG and DIPG } \\
\text { SIX family }\end{array}$ \\
$\begin{array}{c}\text { Proven role in mesenchymal transition in adult HGG, no available data on pediatric HGG and DIPG. Expression data } \\
\text { suggest inferior role in DIPG compared to adult and pediatric supratentorial HGG }\end{array}$
\end{tabular}

in the development and progression of DIPG, currently available Smoothened inhibitors may be used to interfere with the mesenchymal transition in this type of cancer. Within the paradigm of the mesenchymal transition, these drugs would only serve as therapy sensitizers, and should therefore always be combined with other cytotoxic therapeutics or radiotherapy. Finally, over the past years, it has become clear that a large part of pediatric HGG and DIPG are driven by mutations in genes encoding the Histone 3 protein. These mutations either induce a K27M or G34R/V substitution in the N-terminal end of the Histone 3 protein, thereby preventing histone methyltransferases from methylating H3K27 or H3K36 and causing a global epigenetic shift [3-7, 270]. This hypomethylation of Histone 3 at the K27 or K36 residues causes genome-wide changes in gene expression. Of these, the gene expression changes induced by the H3K27M mutation have been extensively investigated [270-273]. Despite this thorough research, the influence of the Histone 3 mutations on the expression of genes involved in the mesenchymal transition has not been specifically addressed yet. Given the observation that differences in expression of mesenchymal genes exist between DIPG carrying a H3.1 or H3.3 K27M mutation, it is not unlikely that the epigenetic shift induced by these mutations 
Table 2 Summary of major signaling pathways involved in the mesenchymal transition and their role in adult GBM, pediatric HGG and DIPG

Signaling pathway Relevance in adult GBM, pediatric HGG and DIPG

TGF- $\beta$ /activin Proven role for classic TGF- $\beta$ signaling in mesenchymal transition in adult GBM, insufficient data on pediatric HGG and DIPG. The presence of ACVR1 mutations in DIPG suggests important role for activin signaling in mesenchymal transition in these tumors

WNT/ $/$-catenin Proven role of canonical WNT signaling in mesenchymal transition in adult GBM, likely limited role in pediatric HGG, insufficient data on DIPG. Non-canonical WNT signaling seems to have a role in mesenchymal transition in adult GBM; no data is available on pediatric HGG and DIPG

$\mathrm{PI}_{3} \mathrm{~K} / \mathrm{AKT} \quad$ Strong suggestions for role in mesenchymal transition in adult GBM, pediatric HGG and DIPG. RTK overexpression and activation and $\mathrm{PI}_{3} \mathrm{~K}$ mutations in pediatric HGG and DIPG support this role

RAS/MAPK Suggestions for role of increased RAS/MAPK signaling in mesenchymal transition in adult GBM, insufficient data on pediatric HGG and DIPG. Mutations in BRAF and NF1 may have a role in some patients. Pathway activation and possible induction of mesenchymal transition is largely mediated by RTK overexpression and activation in these tumors

TAM RTK family Proven role for AXL and MERTK in mesenchymal transition in adult GBM and pediatric HGG, no data on DIPG

JAK/STAT

Suggested role in mesenchymal transition in adult GBM, pediatric HGG and GBM. Possible involvement of overexpressed IL-4 and IL-13 receptors in JAK/STAT-mediated induction of mesenchymal transition in pHGG and DIPG

Sonic hedgehog Strongly suggested role in mesenchymal transition in adult GBM. Proven important in initiation and progression of DIPG, although connection with mesenchymal transition not described. No data available on pediatric HGG with regard to mesenchymal transition

NOTCH Suggested role in mesenchymal transition in adult GBM, insufficient data concerning pediatric HGG and DIPG

Hypoxia Suggested role in mesenchymal transition in adult and pediatric HGG, data lacking on DIPG

is capable of influencing or even inducing the mesenchymal transition in these tumors [38]. These preliminary data warrant further investigation of the connection between Histone 3 mutations, the resulting changes in histone methylation, and the mesenchymal transition in these tumors.

Open Access This article is distributed under the terms of the Creative Commons Attribution 4.0 International License (http://creativecommons.org/licenses/by/4.0/), which permits unrestricted use, distribution, and reproduction in any medium, provided you give appropriate credit to the original author(s) and the source, provide a link to the Creative Commons license, and indicate if changes were made.

\section{References}

1. Gajjar A, Packer RJ, Foreman NK, Cohen K, Haas-Kogan D, Merchant TE (2013) Children's Oncology Group's 2013 blueprint for research: central nervous system tumors. Pediatr Blood Cancer 60:1022-1026

2. van Zanten SEMV et al (2017) External validation of the diffuse intrinsic pontine glioma survival prediction model: a collaborative report from the International DIPG Registry and the SIOPE DIPG Registry. J Neurooncol 134:231-240

3. Jones C, Baker SJ (2014) Unique genetic and epigenetic mechanisms driving paediatric diffuse high-grade glioma. Nat Rev Cancer 14:651-661

4. Khuong-Quang DA et al (2012) K27 M mutation in histone H3.3 defines clinically and biologically distinct subgroups of pediatric diffuse intrinsic pontine gliomas. Acta Neuropathol 124:439-447

5. Schwartzentruber J et al (2012) Driver mutations in histone H3.3 and chromatin remodelling genes in paediatric glioblastoma. Nature 482:226-231

6. Sturm D et al (2012) Hotspot mutations in H3F3A and IDH1 define distinct epigenetic and biological subgroups of glioblastoma. Cancer Cell 22:425-437
7. Wu G et al (2012) Somatic histone $\mathrm{H} 3$ alterations in pediatric diffuse intrinsic pontine gliomas and non-brainstem glioblastomas. Nat Genet 44:251-253

8. Hamisch C, Kickingereder P, Fischer M, Simon T, Ruge MI (2017) Update on the diagnostic value and safety of stereotactic biopsy for pediatric brainstem tumors: a systematic review and meta-analysis of 735 cases. J Neurosurg Pediatr 20:261-268

9. Jakacki RI et al (2016) Phase 2 study of concurrent radiotherapy and temozolomide followed by temozolomide and lomustine in the treatment of children with high-grade glioma: a report of the Children's Oncology Group ACNS0423 study. Neuro Oncol 18:1442-1450

10. Donaldson SS, Laningham F, Fisher PG (2006) Advances toward an understanding of brainstem gliomas. J Clin Oncol 24:1266-1272

11. Lamouille S, Xu J, Derynck R (2014) Molecular mechanisms of epithelial-mesenchymal transition. Nat Rev Mol Cell Biol 15:178-196

12. Carro MS et al (2010) The transcriptional network for mesenchymal transformation of brain tumours. Nature 463:318-325

13. Raggi C, Mousa HS, Correnti M, Sica A, Invernizzi P (2016) Cancer stem cells and tumor-associated macrophages: a roadmap for multitargeting strategies. Oncogene 35:671-682

14. Phillips HS et al (2006) Molecular subclasses of high-grade glioma predict prognosis, delineate a pattern of disease progression, and resemble stages in neurogenesis. Cancer Cell 9:157-173

15. Ducray F et al (2010) An ANOCEF genomic and transcriptomic microarray study of the response to radiotherapy or to alkylating first-line chemotherapy in glioblastoma patients. Mol Cancer 9:234

16. Batlle E, Sancho E, Franci C, Dominguez D, Monfar M, Baulida J, de Garcia HA (2000) The transcription factor snail is a repressor of E-cadherin gene expression in epithelial tumour cells. Nat Cell Biol 2:84-89

17. Dong C et al (2013) Interaction with Suv39H1 is critical for Snail-mediated E-cadherin repression in breast cancer. Oncogene 32:1351-1362 
18. Ghahhari NM, Babashah S (2015) Interplay between microRNAs and WNT/beta-catenin signalling pathway regulates epithelialmesenchymal transition in cancer. Eur J Cancer 51:1638-1649

19. Kaufhold S, Bonavida B (2014) Central role of Snaill in the regulation of EMT and resistance in cancer: a target for therapeutic intervention. J Exp Clin Cancer Res 33:62

20. Wang $\mathrm{H}$ et al (2014) Acquisition of epithelial-mesenchymal transition phenotype and cancer stem cell-like properties in cisplatin-resistant lung cancer cells through AKT/beta-catenin/ Snail signaling pathway. Eur J Pharmacol 723:156-166

21. Alves CC, Carneiro F, Hoefler H, Becker KF (2009) Role of the epithelial-mesenchymal transition regulator Slug in primary human cancers. Front Biosci 14:3035-3050 (Landmark. Ed)

22. Fenouille $\mathrm{N}$ et al (2012) The epithelial-mesenchymal transition (EMT) regulatory factor SLUG (SNAI2) is a downstream target of SPARC and AKT in promoting melanoma cell invasion. PLoS One 7:e40378

23. Villagrasa P et al (2012) Akt2 interacts with Snail1 in the E-cadherin promoter. Oncogene 31:4022-4033

24. Lin Y, Dong C, Zhou BP (2014) Epigenetic regulation of EMT: the Snail story. Curr Pharm Des 20:1698-1705

25. Wang Y, Shang Y (2013) Epigenetic control of epithelial-tomesenchymal transition and cancer metastasis. Exp Cell Res 319:160-169

26. Satelli A, Li S (2011) Vimentin in cancer and its potential as a molecular target for cancer therapy. Cell Mol Life Sci 68:3033-3046

27. Jung HY, Fattet L, Yang J (2015) Molecular pathways: linking tumor microenvironment to epithelial-mesenchymal transition in metastasis. Clin Cancer Res 21:962-968

28. Liu ZC et al (2014) Snail regulated by PKC/GSK-3beta pathway is crucial for EGF-induced epithelial-mesenchymal transition (EMT) of cancer cells. Cell Tissue Res 358:491-502

29. Sun M, Song L, Zhou T, Gillespie GY, Jope RS (2011) The role of DDX3 in regulating Snail. Biochim Biophys Acta 1813:438-447

30. Hahn S, Jackstadt R, Siemens H, Hunten S, Hermeking H (2013) SNAIL and miR-34a feed-forward regulation of ZNF281/ ZBP99 promotes epithelial-mesenchymal transition. EMBO J 32:3079-3095

31. Wang Y, Shi J, Chai K, Ying X, Zhou BP (2013) The role of Snail in EMT and tumorigenesis. Curr Cancer Drug Targets 13:963-972

32. Casas E, Kim J, Bendesky A, Ohno-Machado L, Wolfe CJ, Yang J (2011) Snail2 is an essential mediator of Twist1-induced epithelial mesenchymal transition and metastasis. Cancer Res $71: 245-254$

33. Guaita $\mathrm{S}$ et al (2002) Snail induction of epithelial to mesenchymal transition in tumor cells is accompanied by MUC1 repression and ZEB1 expression. J Biol Chem 277:39209-39216

34. Mahabir R et al (2014) Sustained elevation of Snail promotes glial-mesenchymal transition after irradiation in malignant glioma. Neuro Oncol 16:671-685

35. Savary K et al (2013) Snail depletes the tumorigenic potential of glioblastoma. Oncogene 32:5409-5420

36. Han SP et al (2011) SNAI1 is involved in the proliferation and migration of glioblastoma cells. Cell Mol Neurobiol 31:489-496

37. Kuhnol CD, Wurfel C, Staege MS, Kramm C (2017) Snail homolog 1 is involved in epithelial-mesenchymal transition-like processes in human glioblastoma cells. Oncol Lett 13:3882-3888

38. Puget $S$ et al (2012) Mesenchymal transition and PDGFRA amplification/mutation are key distinct oncogenic events in pediatric diffuse intrinsic pontine gliomas. PLoS One 7:e30313

39. Myung J, Cho BK, Kim YS, Park SH (2010) Snail and Cox-2 expressions are associated with WHO tumor grade and survival rate of patients with gliomas. Neuropathology 30:224-231
40. Yang HW, Menon LG, Black PM, Carroll RS, Johnson MD (2010) SNAI2/Slug promotes growth and invasion in human gliomas. BMC Cancer 10:301

41. Hill L, Browne G, Tulchinsky E (2013) ZEB/miR-200 feedback loop: at the crossroads of signal transduction in cancer. Int $\mathrm{J}$ Cancer 132:745-754

42. Shimono Y et al (2009) Downregulation of miRNA-200c links breast cancer stem cells with normal stem cells. Cell 138:592-603

43. Wellner U et al (2009) The EMT-activator ZEB1 promotes tumorigenicity by repressing stemness-inhibiting microRNAs. Nat Cell Biol 11:1487-1495

44. Cieply B, Farris J, Denvir J, Ford HL, Frisch SM (2013) Epithelial-mesenchymal transition and tumor suppression are controlled by a reciprocal feedback loop between ZEB1 and Grainyheadlike-2. Cancer Res 73:6299-6309

45. Siebzehnrubl FA et al (2013) The ZEB1 pathway links glioblastoma initiation, invasion and chemoresistance. EMBO Mol Med 5:1196-1212

46. Kahlert UD et al (2015) ZEB1 promotes invasion in human fetal neural stem cells and hypoxic glioma neurospheres. Brain Pathol 25:724-732

47. Zhang L et al (2016) SHP-2-upregulated ZEB1 is important for PDGFRalpha-driven glioma epithelial-mesenchymal transition and invasion in mice and humans. Oncogene 35:5641-5652

48. Paugh BS et al (2011) Genome-wide analyses identify recurrent amplifications of receptor tyrosine kinases and cell-cycle regulatory genes in diffuse intrinsic pontine glioma. J Clin Oncol 29:3999-4006

49. Paugh BS et al (2010) Integrated molecular genetic profiling of pediatric high-grade gliomas reveals key differences with the adult disease. J Clin Oncol 28:3061-3068

50. Wu G et al (2014) The genomic landscape of diffuse intrinsic pontine glioma and pediatric non-brainstem high-grade glioma. Nat Genet 46:444-450

51. Qi S et al (2012) ZEB2 mediates multiple pathways regulating cell proliferation, migration, invasion, and apoptosis in glioma. PLoS One 7:e38842

52. Yeasmin S et al (2011) Loss of MKK4 expression in ovarian cancer: a potential role for the epithelial to mesenchymal transition. Int J Cancer 128:94-104

53. Ma L, Teruya-Feldstein J, Weinberg RA (2007) Tumour invasion and metastasis initiated by microRNA-10b in breast cancer. Nature 449:682-688

54. Li X et al (2011) miRNA-223 promotes gastric cancer invasion and metastasis by targeting tumor suppressor EPB41L3. Mol Cancer Res 9:824-833

55. Sullivan NJ, Sasser AK, Axel AE, Vesuna F, Raman V, Ramirez N, Oberyszyn TM, Hall BM (2009) Interleukin-6 induces an epithelial-mesenchymal transition phenotype in human breast cancer cells. Oncogene 28:2940-2947

56. Nordfors K et al (2015) Twist predicts poor outcome of patients with astrocytic glioma. J Clin Pathol 68:905-912

57. Krossa S, Schmitt AD, Hattermann K, Fritsch J, Scheidig AJ, Mehdorn HM, Held-Feindt J (2015) Down regulation of Akirin-2 increases chemosensitivity in human glioblastomas more efficiently than Twist-1. Oncotarget 6:21029-21045

58. Velpula KK, Dasari VR, Tsung AJ, Dinh DH, Rao JS (2011) Cord blood stem cells revert glioma stem cell EMT by down regulating transcriptional activation of Sox 2 and Twist1. Oncotarget 2:1028-1042

59. Iwanaga $\mathrm{R}$ et al (2012) Expression of Six 1 in luminal breast cancers predicts poor prognosis and promotes increases in tumor initiating cells by activation of extracellular signal-regulated kinase and transforming growth factor-beta signaling pathways. Breast Cancer Res 14:R100 
60. Li Z et al (2014) Targeting Six 1 by lentivirus-mediated RNA interference inhibits colorectal cancer cell growth and invasion. Int J Clin Exp Pathol 7:631-639

61. Micalizzi DS et al (2009) The Six1 homeoprotein induces human mammary carcinoma cells to undergo epithelial-mesenchymal transition and metastasis in mice through increasing TGF- $\hat{I}^{2}$ signaling. J Clin Invest 119:2678-2690

62. Xu H, Zhang Y, Altomare D, Peña MM, Wan F, Pirisi L, Creek KE (2014) Six 1 promotes epithelial-mesenchymal transition and malignant conversion in human papillomavirus type 16-immortalized human keratinocytes. Carcinogenesis 35:1379-1388

63. Ono H et al (2012) SIX1 promotes epithelial-mesenchymal transition in colorectal cancer through ZEB1 activation. Oncogene 31:4923-4934

64. McCoy EL, Iwanaga R, Jedlicka P, Abbey NS, Chodosh LA, Heichman KA, Welm AL, Ford HL (2009) Six 1 expands the mouse mammary epithelial stem/progenitor cell pool and induces mammary tumors that undergo epithelial-mesenchymal transition. J Clin Invest 119:2663-2677

65. Tian T, Li A, Lu H, Luo R, Zhang M, Li Z (2015) Six 1 promotes glioblastoma cell proliferation and invasion by upregulation of connective tissue growth factor. Am J Cancer Res 5:1823-1830

66. Auvergne RM et al (2013) Transcriptional differences between normal and glioma-derived glial progenitor cells identify a core set of dysregulated genes. Cell Rep 3:2127-2141

67. Massague J, Seoane J, Wotton D (2005) Smad transcription factors. Genes Dev 19:2783-2810

68. Bakin AV, Tomlinson AK, Bhowmick NA, Moses HL, Arteaga CL (2000) Phosphatidylinositol 3-kinase function is required for transforming growth factor beta-mediated epithelial to mesenchymal transition and cell migration. J Biol Chem 275:36803-36810

69. Derynck R, Zhang YE (2003) Smad-dependent and Smadindependent pathways in TGF-beta family signalling. Nature 425:577-584

70. Buczkowicz P et al (2014) Genomic analysis of diffuse intrinsic pontine gliomas identifies three molecular subgroups and recurrent activating ACVR1 mutations. Nat Genet 46:451-456

71. Taylor KR et al (2014) Recurrent activating ACVR1 mutations in diffuse intrinsic pontine glioma. Nat Genet 46:457-461

72. Bramlage CP et al (2010) Bone morphogenetic protein (BMP)-7 expression is decreased in human hypertensive nephrosclerosis. BMC Nephrol 11:31

73. Fontebasso AM et al (2014) Recurrent somatic mutations in ACVR1 in pediatric midline high-grade astrocytoma. Nat Genet 46:462-466

74. Meng XM, Chung AC, Lan HY (2013) Role of the TGF-beta/ BMP-7/Smad pathways in renal diseases. Clin Sci (Lond) 124:243-254

75. Adler PN, Krasnow RE, Liu J (1997) Tissue polarity points from cells that have higher Frizzled levels towards cells that have lower Frizzled levels. Curr Biol 7:940-949

76. Bhanot $P$ et al (1996) A new member of the frizzled family from Drosophila functions as a Wingless receptor. Nature 382:225-230

77. Hey PJ et al (1998) Cloning of a novel member of the low-density lipoprotein receptor family. Gene 216:103-111

78. Brown SD et al (1998) Isolation and characterization of LRP6, a novel member of the low density lipoprotein receptor gene family. Biochem Biophys Res Commun 248:879-888

79. Aberle H, Bauer A, Stappert J, Kispert A, Kemler R (1997) betacatenin is a target for the ubiquitin-proteasome pathway. EMBO J 16:3797-3804

80. Ikeda S, Kishida S, Yamamoto H, Murai H, Koyama S, Kikuchi A (1998) Axin, a negative regulator of the Wnt signaling pathway, forms a complex with GSK-3beta and beta-catenin and promotes GSK-3beta-dependent phosphorylation of beta-catenin. EMBO J 17:1371-1384

81. Fagotto F, Gluck U, Gumbiner BM (1998) Nuclear localization signal-independent and importin/karyopherin-independent nuclear import of beta-catenin. Curr Biol 8:181-190

82. Yokoya F, Imamoto N, Tachibana T, Yoneda Y (1999) betacatenin can be transported into the nucleus in a Ran-unassisted manner. Mol Biol Cell 10:1119-1131

83. Ille F, Sommer L (2005) Wnt signaling: multiple functions in neural development. Cell Mol Life Sci 62:1100-1108

84. Nusse R (1999) WNT targets. Repression and activation. Trends Genet 15:1-3

85. Nawshad A, Medici D, Liu CC, Hay ED (2007) TGFbeta3 inhibits E-cadherin gene expression in palate medial-edge epithelial cells through a Smad2-Smad4-LEF1 transcription complex. J Cell Sci 120:1646-1653

86. Xu W, Wang Z, Zhang W, Qian K, Li H, Kong D, Li Y, Tang Y (2015) Mutated K-ras activates CDK8 to stimulate the epithelialto-mesenchymal transition in pancreatic cancer in part via the Wnt/beta-catenin signaling pathway. Cancer Lett 356:613-627

87. Wu ZQ, Li XY, Hu CY, Ford M, Kleer CG, Weiss SJ (2012) Canonical Wnt signaling regulates Slug activity and links epithelial-mesenchymal transition with epigenetic Breast Cancer 1, Early Onset (BRCA1) repression. Proc Natl Acad Sci USA 109:16654-16659

88. Zhao JH, Luo Y, Jiang YG, He DL, Wu CT (2011) Knockdown of beta-Catenin through shRNA cause a reversal of EMT and metastatic phenotypes induced by HIF-1alpha. Cancer Invest 29:377-382

89. Chen L et al (2014) A lentivirus-mediated miR-23b sponge diminishes the malignant phenotype of glioma cells in vitro and in vivo. Oncol Rep 31:1573-1580

90. Zhang Q et al (2013) Wnt/beta-catenin signaling enhances hypoxia-induced epithelial-mesenchymal transition in hepatocellular carcinoma via crosstalk with hif-1alpha signaling. Carcinogenesis 34:962-973

91. Rossi M et al (2011) beta-catenin and Gli1 are prognostic markers in glioblastoma. Cancer Biol Ther 11:753-761

92. Liu C et al (2011) Wnt/beta-Catenin pathway in human glioma: expression pattern and clinical/prognostic correlations. Clin Exp Med 11:105-112

93. Zhang LY et al (2010) Reduced beta-catenin expression is associated with good prognosis in Astrocytoma. Pathol Oncol Res $16: 253-257$

94. Kamino M et al (2011) Wnt-5a signaling is correlated with infiltrative activity in human glioma by inducing cellular migration and MMP-2. Cancer Sci 102:540-548

95. Liu X, Wang L, Zhao S, Ji X, Luo Y, Ling F (2011) beta-Catenin overexpression in malignant glioma and its role in proliferation and apoptosis in glioblastma cells. Med Oncol 28:608-614

96. Sareddy GR, Panigrahi M, Challa S, Mahadevan A, Babu PP (2009) Activation of Wnt/beta-catenin/Tcf signaling pathway in human astrocytomas. Neurochem Int 55:307-317

97. Kahlert UD et al (2012) Activation of canonical WNT/betacatenin signaling enhances in vitro motility of glioblastoma cells by activation of ZEB1 and other activators of epithelial-tomesenchymal transition. Cancer Lett 325:42-53

98. Nie E, Zhang X, Xie S, Shi Q, Hu J, Meng Q, Zhou X, Yu R (2015) Beta-catenin is involved in Bex2 down-regulation induced glioma cell invasion/migration inhibition. Biochem Biophys Res Commun 456:494-499

99. Zhang J et al (2011) High beta-catenin/Tcf-4 activity confers glioma progression via direct regulation of AKT2 gene expression. Neuro Oncol 13:600-609

100. Rampazzo E et al (2013) Wnt activation promotes neuronal differentiation of glioblastoma. Cell Death Dis 4:e500 
101. Kaur N, Chettiar S, Rathod S, Rath P, Muzumdar D, Shaikh ML, Shiras A (2013) Wnt3a mediated activation of Wnt/beta-catenin signaling promotes tumor progression in glioblastoma. Mol Cell Neurosci 54:44-57

102. Wang K, Park JO, Zhang M (2013) Treatment of glioblastoma multiforme using a combination of small interfering RNA targeting epidermal growth factor receptor and beta-catenin. J Gene Med 15:42-50

103. Kim Y et al (2012) Wnt activation is implicated in glioblastoma radioresistance. Lab Invest 92:466-473

104. Zhukova N et al (2014) WNT activation by lithium abrogates TP53 mutation associated radiation resistance in medulloblastoma. Acta Neuropathol Commun 2:174

105. Bhuvanalakshmi G, Arfuso F, Millward M, Dharmarajan A, Warrier S (2015) Secreted frizzled-related protein 4 inhibits glioma stem-like cells by reversing epithelial to mesenchymal transition, inducing apoptosis and decreasing cancer stem cell properties. PLoS One 10:e0127517

106. Warrier S, Balu SK, Kumar AP, Millward M, Dharmarajan A (2013) Wnt antagonist, secreted frizzled-related protein 4 (sFRP4), increases chemotherapeutic response of glioma stemlike cells. Oncol Res 21:93-102

107. Wiese $\mathrm{M}$ et al (2017) The beta-catenin/CBP-antagonist ICG-001 inhibits pediatric glioma tumorigenicity in a Wnt-independent manner. Oncotarget 8:27300-27313

108. Komiya Y, Habas R (2008) Wnt signal transduction pathways. Organogenesis 4:68-75

109. Grumolato L et al (2010) Canonical and noncanonical Wnts use a common mechanism to activate completely unrelated coreceptors. Genes Dev 24:2517-2530

110. Bo H, Zhang S, Gao L, Chen Y, Zhang J, Chang X, Zhu M (2013) Upregulation of Wnt5a promotes epithelial-to-mesenchymal transition and metastasis of pancreatic cancer cells. BMC Cancer 13:496

111. Ren D, Minami Y, Nishita M (2011) Critical role of Wnt5a-Ror2 signaling in motility and invasiveness of carcinoma cells following Snail-mediated epithelial-mesenchymal transition. Genes Cells 16:304-315

112. Asano T et al (2017) Clinical implication of Frizzled 2 expression and its association with epithelial-to-mesenchymal transition in hepatocellular carcinoma. Int J Oncol 50:1647-1654

113. Ford CE et al (2014) The non-canonical Wnt ligand, Wnt5a, is upregulated and associated with epithelial to mesenchymal transition in epithelial ovarian cancer. Gynecol Oncol 134:338-345

114. Zhang Y et al (2015) EGF-reduced Wnt5a transcription induces epithelial-mesenchymal transition via Arf6-ERK signaling in gastric cancer cells. Oncotarget 6:7244-7261

115. Binda $\mathrm{E}$ et al (2017) Wnt5a drives an invasive phenotype in human glioblastoma stem-like cells. Cancer Res 77:996-1007

116. Hirano $\mathrm{H}$ et al (2014) Immunoreactivity of Wnt5a, Fzd2, Fzd6, and Ryk in glioblastoma: evaluative methodology for DAB chromogenic immunostaining. Brain Tumor Pathol 31:85-93

117. Hu B et al (2016) Epigenetic activation of WNT5A drives glioblastoma stem cell differentiation and invasive growth. Cell 167(1281-1295):e18

118. Kim Y, Hong M, Do IG, Ha SY, Lee D, Suh YL (2015) Wnt5a, Ryk and Ror2 expression in glioblastoma subgroups. Pathol Res Pract 211:963-972

119. Pulvirenti T, Van Der Heijden M, Droms LA, Huse JT, Tabar V, Hall A (2011) Dishevelled 2 signaling promotes self-renewal and tumorigenicity in human gliomas. Cancer Res 71:7280-7290

120. Vassallo I, Zinn P, Lai M, Rajakannu P, Hamou MF, Hegi ME (2016) WIF1 re-expression in glioblastoma inhibits migration through attenuation of non-canonical WNT signaling by downregulating the lncRNA MALAT1. Oncogene 35:12-21
121. Wald JH et al (2017) Suppression of planar cell polarity signaling and migration in glioblastoma by Nrdp1-mediated Dvl polyubiquitination. Oncogene 36:5158-5167

122. Yu JM, Jun ES, Jung JS, Suh SY, Han JY, Kim JY, Kim KW, Jung JS (2007) Role of Wnt5a in the proliferation of human glioblastoma cells. Cancer Lett 257:172-181

123. Zhou BP, Deng J, Xia W, Xu J, Li YM, Gunduz M, Hung MC (2004) Dual regulation of Snail by GSK-3beta-mediated phosphorylation in control of epithelial-mesenchymal transition. Nat Cell Biol 6:931-940

124. Bachelder RE, Yoon SO, Franci C, De Herreros AG, Mercurio AM (2005) Glycogen synthase kinase-3 is an endogenous inhibitor of Snail transcription: implications for the epithelialmesenchymal transition. J Cell Biol 168:29-33

125. Wu K et al (2012) PI3 K/Akt to GSK3beta/beta-catenin signaling cascade coordinates cell colonization for bladder cancer bone metastasis through regulating ZEB1 transcription. Cell Signal 24:2273-2282

126. Peng $\mathrm{C}$ et al (2015) The 14-3-3sigma/GSK3beta/beta-catenin/ ZEB1 regulatory loop modulates chemo-sensitivity in human tongue cancer. Oncotarget 6:20177-20189

127. Xue G, Restuccia DF, Lan Q, Hynx D, Dirnhofer S, Hess D, Ruegg C, Hemmings BA (2012) Akt/PKB-mediated phosphorylation of Twist 1 promotes tumor metastasis via mediating crosstalk between PI3 K/Akt and TGF-beta signaling axes. Cancer Discov 2:248-259

128. Wang $\mathrm{H}$ et al (2013) Epithelial-mesenchymal transition (EMT) induced by TNF-alpha requires AKT/GSK-3beta-mediated stabilization of snail in colorectal cancer. PLoS One 8:e56664

129. Maseki $S$ et al (2012) Acquisition of EMT phenotype in the gefitinib-resistant cells of a head and neck squamous cell carcinoma cell line through Akt/GSK-3beta/snail signalling pathway. Br J Cancer 106:1196-1204

130. Jiao M, Nan KJ (2012) Activation of PI3 kinase/Akt/HIF-1alpha pathway contributes to hypoxia-induced epithelial-mesenchymal transition and chemoresistance in hepatocellular carcinoma. Int J Oncol 40:461-468

131. Chang L, Graham PH, Hao J, Ni J, Bucci J, Cozzi PJ, Kearsley JH, Li Y (2013) Acquisition of epithelial-mesenchymal transition and cancer stem cell phenotypes is associated with activation of the PI3 K/Akt/mTOR pathway in prostate cancer radioresistance. Cell Death Dis 4:e875

132. Baryawno N, Sveinbjornsson B, Eksborg S, Chen CS, Kogner P, Johnsen JI (2010) Small-molecule inhibitors of phosphatidylinositol 3-kinase/Akt signaling inhibit Wnt/beta-catenin pathway cross-talk and suppress medulloblastoma growth. Cancer Res 70:266-276

133. Blum R, Jacob-Hirsch J, Amariglio N, Rechavi G, Kloog Y (2005) Ras inhibition in glioblastoma down-regulates hypoxiainducible factor-1alpha, causing glycolysis shutdown and cell death. Cancer Res 65:999-1006

134. Han L et al (2010) Inactivation of PI3 K/AKT signaling inhibits glioma cell growth through modulation of beta-catenin-mediated transcription. Brain Res 1366:9-17

135. Pore N, Jiang Z, Shu HK, Bernhard E, Kao GD, Maity A (2006) Akt1 activation can augment hypoxia-inducible factor-1alpha expression by increasing protein translation through a mammalian target of rapamycin-independent pathway. Mol. Cancer Res $4: 471-479$

136. Kwak HJ et al (2011) Downregulation of Spry 2 by miR-21 triggers malignancy in human gliomas. Oncogene 30:2433-2442

137. Choi EJ, Cho BJ, Lee DJ, Hwang YH, Chun SH, Kim HH, Kim IA (2014) Enhanced cytotoxic effect of radiation and temozolomide in malignant glioma cells: targeting PI3 K-AKT-mTOR signaling, HSP90 and histone deacetylases. BMC Cancer 14:17 
138. Robison NJ, Kieran MW (2012) Identification of novel biologic targets in the treatment of newly diagnosed diffuse intrinsic pontine glioma. In: 2012 ASCO annual meeting, vol 2, pp 625-628

139. Grill J, Puget S, Andreiuolo F, Philippe C, MacConaill L, Kieran MW (2012) Critical oncogenic mutations in newly diagnosed pediatric diffuse intrinsic pontine glioma. Pediatr Blood Cancer 58:489-491

140. Nikbakht $\mathrm{H}$ et al (2016) Spatial and temporal homogeneity of driver mutations in diffuse intrinsic pontine glioma. Nat Commun $7: 11185$

141. Kim EK, Choi EJ (2015) Compromised MAPK signaling in human diseases: an update. Arch Toxicol 89:867-882

142. Makrodouli E, Oikonomou E, Koc M, Andera L, Sasazuki T, Shirasawa S, Pintzas A (2011) BRAF and RAS oncogenes regulate Rho GTPase pathways to mediate migration and invasion properties in human colon cancer cells: a comparative study. Mol Cancer 10:118

143. Hong J, Zhou J, Fu J, He T, Qin J, Wang L, Liao L, Xu J (2011) Phosphorylation of serine 68 of Twist 1 by MAPKs stabilizes Twist1 protein and promotes breast cancer cell invasiveness. Cancer Res 71:3980-3990

144. Grande M, Franzen A, Karlsson JO, Ericson LE, Heldin NE, Nilsson M (2002) Transforming growth factor-beta and epidermal growth factor synergistically stimulate epithelial to mesenchymal transition (EMT) through a MEK-dependent mechanism in primary cultured pig thyrocytes. J Cell Sci 115:4227-4236

145. Chen X, Xiao W, Wang W, Luo L, Ye S, Liu Y (2014) The complex interplay between ERK1/2, TGFbeta/Smad, and Jagged/ Notch signaling pathways in the regulation of epithelial-mesenchymal transition in retinal pigment epithelium cells. PLoS One 9:e96365

146. Mulholland DJ, Kobayashi N, Ruscetti M, Zhi A, Tran LM, Huang J, Gleave M, Wu H (2012) Pten loss and RAS/MAPK activation cooperate to promote EMT and metastasis initiated from prostate cancer stem/progenitor cells. Cancer Res 72:1878-1889

147. Lin K, Baritaki S, Militello L, Malaponte G, Bevelacqua Y, Bonavida B (2010) The role of B-RAF mutations in melanoma and the induction of EMT via dysregulation of the NF-kappaB/Snail/ RKIP/PTEN circuit. Genes Cancer 1:409-420

148. Koh $\mathrm{M}$ et al (2015) Discoidin domain receptor 1 is a novel transcriptional target of ZEB1 in breast epithelial cells undergoing H-Ras-induced epithelial to mesenchymal transition. Int J Cancer 136:E508-E520

149. Shao DD et al (2014) KRAS and YAP1 converge to regulate EMT and tumor survival. Cell 158:171-184

150. Voon DC et al (2013) EMT-induced stemness and tumorigenicity are fueled by the EGFR/Ras pathway. PLoS One 8:e70427

151. Botta GP, Reginato MJ, Reichert M, Rustgi AK, Lelkes PI (2012) Constitutive K-RasG12D activation of ERK2 specifically regulates 3D invasion of human pancreatic cancer cells via MMP-1. Mol Cancer Res 10:183-196

152. Nagarajan D, Melo T, Deng Z, Almeida C, Zhao W (2012) ERK/ GSK3beta/Snail signaling mediates radiation-induced alveolar epithelial-to-mesenchymal transition. Free Radic Biol Med 52:983-992

153. Zhang W et al (2012) Down-regulation of CMTM8 induces epithelial-to-mesenchymal transition-like changes via c-MET/ extracellular signal-regulated kinase (ERK) signaling. J Biol Chem 287:11850-11858

154. Nguyen PT, Tsunematsu T, Yanagisawa S, Kudo Y, Miyauchi M, Kamata N, Takata T (2013) The FGFR1 inhibitor PD173074 induces mesenchymal-epithelial transition through the transcription factor AP-1. Br J Cancer 109:2248-2258
155. Lassaletta A et al (2017) Therapeutic and prognostic implications of BRAF V600E in pediatric low-grade gliomas. J Clin Oncol 35:2934-2941

156. Lo HW (2010) Targeting Ras-RAF-ERK and its interactive pathways as a novel therapy for malignant gliomas. Curr Cancer Drug Targets 10:840-848

157. Jones C, Baker SJ (2014) Unique genetic and epigenetic mechanisms driving paediatric diffuse high-grade glioma. Nat Rev Cancer 14:651-661

158. Truong AY, Nicolaides TP (2015) Targeted therapy for MAPK alterations in pediatric gliomas. Brain Disord, Ther Suppl, p 2

159. Karajannis MA et al (2014) Phase II study of sorafenib in children with recurrent or progressive low-grade astrocytomas. Neuro Oncol 16:1408-1416

160. Linger RMA, Keating AK, Earp HS, Graham DK (2008) TAM receptor tyrosine kinases: biologic functions, signaling, and potential therapeutic targeting in human cancer. Adv Cancer Res 100:35-83

161. Meyer AS, Miller MA, Gertler FB, Lauffenburger DA (2013) The receptor AXL diversifies EGFR signaling and limits the response to EGFR-targeted inhibitors in triple-negative breast cancer cells. Sci Signal 6:ra66

162. Lee HJ, Jeng YM, Chen YL, Chung L, Yuan RH (2014) Gas6/ Axl pathway promotes tumor invasion through the transcriptional activation of Slug in hepatocellular carcinoma. Carcinogenesis 35:769-775

163. Reichl P et al (2015) Axl activates autocrine transforming growth factor-beta signaling in hepatocellular carcinoma. Hepatology 61:930-941

164. Dunne PD et al (2014) AXL is a key regulator of inherent and chemotherapy-induced invasion and predicts a poor clinical outcome in early-stage colon cancer. Clin Cancer Res 20:164-175

165. Vuoriluoto K et al (2011) Vimentin regulates EMT induction by Slug and oncogenic H-Ras and migration by governing Axl expression in breast cancer. Oncogene 30:1436-1448

166. Gjerdrum $\mathrm{C}$ et al (2010) $\mathrm{Axl}$ is an essential epithelial-to-mesenchymal transition-induced regulator of breast cancer metastasis and patient survival. Proc Natl Acad Sci USA 107:1124-1129

167. Holland SJ et al (2010) R428, a selective small molecule inhibitor of Axl kinase, blocks tumor spread and prolongs survival in models of metastatic breast cancer. Cancer Res 70:1544-1554

168. Asiedu MK, Beauchamp-Perez FD, Ingle JN, Behrens MD, Radisky DC, Knutson KL (2014) AXL induces epithelial-tomesenchymal transition and regulates the function of breast cancer stem cells. Oncogene 33:1316-1324

169. Cichon MA, Szentpetery Z, Caley MP, Papadakis ES, Mackenzie IC, Brennan CH, O'Toole EA (2014) The receptor tyrosine kinase Axl regulates cell-cell adhesion and stemness in cutaneous squamous cell carcinoma. Oncogene 33:4185-4192

170. Wang Y, Xia H, Zhuang Z, Miao L, Chen X, Cai H (2014) Axlaltered microRNAs regulate tumorigenicity and gefitinib resistance in lung cancer. Cell Death. Dis 5:e1227

171. Wu F, Li J, Jang C, Wang J, Xiong J (2014) The role of Axl in drug resistance and epithelial-to-mesenchymal transition of nonsmall cell lung carcinoma. Int J Clin Exp Pathol 7:6653-6661

172. Byers LA et al (2013) An epithelial-mesenchymal transition gene signature predicts resistance to EGFR and PI3 K inhibitors and identifies Axl as a therapeutic target for overcoming EGFR inhibitor resistance. Clin Cancer Res 19:279-290

173. Zhang $Z$ et al (2012) Activation of the AXL kinase causes resistance to EGFR-targeted therapy in lung cancer. Nat Genet 44:852-860

174. Martinho O, Zucca LE, Reis RM (2015) AXL as a modulator of sunitinib response in glioblastoma cell lines. Exp Cell Res 332:1-10 
175. Vajkoczy P et al (2006) Dominant-negative inhibition of the Axl receptor tyrosine kinase suppresses brain tumor cell growth and invasion and prolongs survival. Proc Natl Acad Sci USA 103:5799-5804

176. Vouri M, An Q, Birt M, Pilkington GJ, Hafizi S (2015) Small molecule inhibition of Axl receptor tyrosine kinase potently suppresses multiple malignant properties of glioma cells. Oncotarget 6:16183-16197

177. Wang Y et al (2013) Mer receptor tyrosine kinase promotes invasion and survival in glioblastoma multiforme. Oncogene 32:872-882

178. Rogers AE, Le JP, Sather S, Pernu BM, Graham DK, Pierce AM, Keating AK (2012) Mer receptor tyrosine kinase inhibition impedes glioblastoma multiforme migration and alters cellular morphology. Oncogene 31:4171-4181

179. Knubel KH, Pernu BM, Sufit A, Nelson S, Pierce AM, Keating AK (2014) MerTK inhibition is a novel therapeutic approach for glioblastoma multiforme. Oncotarget 5:1338-1351

180. Keating AK et al (2010) Inhibition of Mer and Axl receptor tyrosine kinases in astrocytoma cells leads to increased apoptosis and improved chemosensitivity. Mol Cancer Ther 9:1298-1307

181. Meel MH, Sewing ACP, Waranecki P, Metselaar DS, Wedekind LE, Koster J, van Vuurden DG, Kaspers GJL, Hulleman E (2017) Culture methods of diffuse intrinsic pontine glioma cells determine response to targeted therapies. Exp Cell Res 360(2):397403. https://doi.org/10.1016/j.yexcr.2017.09.032

182. Friederichs K, Schmitz J, Weissenbach M, Heinrich PC, Schaper F (2001) Interleukin-6-induced proliferation of pre-B cells mediated by receptor complexes lacking the SHP2/SOCS3 recruitment sites revisited. Eur J Biochem 268:6401-6407

183. Uddin N, Kim RK, Yoo KC, Kim YH, Cui YH, Kim IG, Suh Y, Lee SJ (2015) Persistent activation of STAT3 by PIM2-driven positive feedback loop for epithelial-mesenchymal transition in breast cancer. Cancer Sci 106:718-725

184. Xiong $\mathrm{H}$ et al (2012) Roles of STAT3 and ZEB1 proteins in E-cadherin down-regulation and human colorectal cancer epithelial-mesenchymal transition. J Biol Chem 287:5819-5832

185. Kang SH, Yu MO, Park KJ, Chi SG, Park DH, Chung YG (2010) Activated STAT3 regulates hypoxia-induced angiogenesis and cell migration in human glioblastoma. Neurosurgery 67:1386-1395

186. Zhao D et al (2015) Cytoplasmic p27 promotes epithelial-mesenchymal transition and tumor metastasis via STAT3-mediated Twist1 upregulation. Oncogene 34:5447-5459

187. Lo HW et al (2007) Epidermal growth factor receptor cooperates with signal transducer and activator of transcription 3 to induce epithelial-mesenchymal transition in cancer cells via upregulation of TWIST gene expression. Cancer Res 67:9066-9076

188. Cao F, Hata R, Zhu P, Nakashiro K, Sakanaka M (2010) Conditional deletion of Stat 3 promotes neurogenesis and inhibits astrogliogenesis in neural stem cells. Biochem Biophys Res Commun 394:843-847

189. Yue P, Zhang X, Paladino D, Sengupta B, Ahmad S, Holloway RW, Ingersoll SB, Turkson J (2012) Hyperactive EGF receptor, Jaks and Stat 3 signaling promote enhanced colony-forming ability, motility and migration of cisplatin-resistant ovarian cancer cells. Oncogene 31:2309-2322

190. Chung SS, Giehl N, Wu Y, Vadgama JV (2014) STAT3 activation in HER2-overexpressing breast cancer promotes epithelialmesenchymal transition and cancer stem cell traits. Int J Oncol 44:403-411

191. Kim MJ, Lim J, Yang Y, Lee MS, Lim JS (2014) N-myc downstream-regulated gene 2 (NDRG2) suppresses the epithelialmesenchymal transition (EMT) in breast cancer cells via STAT3/ Snail signaling. Cancer Lett 354:33-42
192. Lu Z et al (2014) FTY720 inhibits proliferation and epithelialmesenchymal transition in cholangiocarcinoma by inactivating STAT3 signaling. BMC Cancer 14:783

193. Kohsaka S et al (2012) STAT3 inhibition overcomes temozolomide resistance in glioblastoma by downregulating MGMT expression. Mol Cancer Ther 11:1289-1299

194. Villalva $\mathrm{C}$ et al (2011) STAT3 is essential for the maintenance of neurosphere-initiating tumor cells in patients with glioblastomas: a potential for targeted therapy? Int J Cancer 128:826-838

195. Wang $Y$ et al (2011) Inhibition of STAT3 reverses alkylator resistance through modulation of the AKT and beta-catenin signaling pathways. Oncol Rep 26:1173-1180

196. Gao L, Li F, Dong B, Zhang J, Rao Y, Cong Y, Mao B, Chen X (2010) Inhibition of STAT3 and ErbB2 suppresses tumor growth, enhances radiosensitivity, and induces mitochondriadependent apoptosis in glioma cells. Int J Radiat Oncol Biol Phys 77:1223-1231

197. Joshi BH, Leland P, Asher A, Prayson RA, Varricchio F, Puri RK (2001) In situ expression of interleukin-4 (IL-4) receptors in human brain tumors and cytotoxicity of a recombinant IL-4 cytotoxin in primary glioblastoma cell cultures. Cancer Res 61:8058-8061

198. Joshi BH, Puri RA, Leland P, Varricchio F, Gupta G, Kocak M, Gilbertson RJ, Puri RK (2008) Identification of interleukin-13 receptor alpha 2 chain overexpression in situ in high-grade diffusely infiltrative pediatric brainstem glioma. Neuro Oncol $10: 265-274$

199. Kawakami M, Kawakami K, Takahashi S, Abe M, Puri RK (2004) Analysis of interleukin-13 receptor alpha2 expression in human pediatric brain tumors. Cancer 101:1036-1042

200. Okada H, Low KL, Kohanbash G, McDonald HA, Hamilton RL, Pollack IF (2008) Expression of glioma-associated antigens in pediatric brain stem and non-brain stem gliomas. J Neurooncol $88: 245-250$

201. Lee Y, Kawagoe R, Sasai K, Li Y, Russell HR, Curran T, McKinnon PJ (2007) Loss of suppressor-of-fused function promotes tumorigenesis. Oncogene 26:6442-6447

202. Gan GN, Jimeno A (2016) Emerging from their burrow: Hedgehog pathway inhibitors for cancer. Expert Opin Investig Drugs 25:1153-1166

203. Fendrich V, Waldmann J, Esni F, Ramaswamy A, Mullendore M, Buchholz M, Maitra A, Feldmann G (2007) Snail and Sonic Hedgehog activation in neuroendocrine tumors of the ileum. Endocr Relat Cancer 14:865-874

204. Katoh Y, Katoh M (2009) Hedgehog target genes: mechanisms of carcinogenesis induced by aberrant hedgehog signaling activation. Curr Mol Med 9:873-886

205. Mimeault M, Batra SK (2011) Complex oncogenic signaling networks regulate brain tumor-initiating cells and their progenies: pivotal roles of wild-type EGFR, EGFRvIII mutant and hedgehog cascades and novel multitargeted therapies. Brain Pathol 21:479-500

206. Schreck KC, Taylor P, Marchionni L, Gopalakrishnan V, Bar EE, Gaiano N, Eberhart CG (2010) The Notch target Hes1 directly modulates Gli1 expression and Hedgehog signaling: a potential mechanism of therapeutic resistance. Clin Cancer Res 16:6060-6070

207. Lei J et al (2015) Gli-1 is crucial for hypoxia-induced epithelialmesenchymal transition and invasion of breast cancer. Tumour Biol 36:3119-3126

208. Yoo YA, Kang MH, Lee HJ, Kim BH, Park JK, Kim HK, Kim JS, Oh SC (2011) Sonic hedgehog pathway promotes metastasis and lymphangiogenesis via activation of Akt, EMT, and MMP-9 pathway in gastric cancer. Cancer Res 71:7061-7070 
209. Takezaki T, Hide T, Takanaga H, Nakamura H, Kuratsu J, Kondo $\mathrm{T}$ (2011) Essential role of the Hedgehog signaling pathway in human glioma-initiating cells. Cancer Sci 102:1306-1312

210. Yan GN et al (2014) Endothelial cells promote stem-like phenotype of glioma cells through activating the Hedgehog pathway. J Pathol 234:11-22

211. Chiang MF et al (2015) Modulation of Sonic hedgehog signaling and WW domain containing oxidoreductase WOX1 expression enhances radiosensitivity of human glioblastoma cells. Exp Biol Med (Maywood.) 240:392-399

212. Fu J, Rodova M, Nanta R, Meeker D, Van Veldhuizen PJ, Srivastava RK, Shankar S (2013) NPV-LDE-225 (Erismodegib) inhibits epithelial mesenchymal transition and self-renewal of glioblastoma initiating cells by regulating miR-21, miR-128, and miR-200. Neuro Oncol 15:691-706

213. Ulasov IV, Nandi S, Dey M, Sonabend AM, Lesniak MS (2011) Inhibition of Sonic hedgehog and Notch pathways enhances sensitivity of CD133(+) glioma stem cells to temozolomide therapy. Mol Med 17:103-112

214. Monje $\mathrm{M}$ et al (2011) Hedgehog-responsive candidate cell of origin for diffuse intrinsic pontine glioma. Proc Natl Acad Sci USA 108:4453-4458

215. Miele L (2006) Notch signaling. Clin Cancer Res 12:1074-1079

216. Cenciarelli C et al (2014) PDGF receptor alpha inhibition induces apoptosis in glioblastoma cancer stem cells refractory to antiNotch and anti-EGFR treatment. Mol Cancer 13:247

217. Guichet PO et al (2015) Notch1 stimulation induces a vascularization switch with pericyte-like cell differentiation of glioblastoma stem cells. Stem Cells 33:21-34

218. Chen X, Xiao W, Liu X, Zeng M, Luo L, Wu M, Ye S, Liu Y (2014) Blockade of Jagged/Notch pathway abrogates transforming growth factor beta2-induced epithelial-mesenchymal transition in human retinal pigment epithelium cells. Curr Mol Med 14:523-534

219. Wang Z, Li Y, Kong D, Sarkar FH (2010) The role of Notch signaling pathway in epithelial-mesenchymal transition (EMT) during development and tumor aggressiveness. Curr Drug Targets 11:745-751

220. Espinoza I, Miele L (2013) Deadly crosstalk: Notch signaling at the intersection of EMT and cancer stem cells. Cancer Lett 341:41-45

221. Alqudah MA, Agarwal S, Al-Keilani MS, Sibenaller ZA, Ryken TC, Assem M (2013) NOTCH3 is a prognostic factor that promotes glioma cell proliferation, migration and invasion via activation of CCND1 and EGFR. PLoS One 8:e77299

222. Jiang L, Wu J, Chen Q, Hu X, Li W, Hu G (2011) Notch1 expression is upregulated in glioma and is associated with tumor progression. J Clin Neurosci 18:387-390

223. Zhang $X$ et al (2012) Notch1 promotes glioma cell migration and invasion by stimulating beta-catenin and NF-kappaB signaling via AKT activation. Cancer Sci 103:181-190

224. Hulleman E et al (2009) A role for the transcription factor HEY1 in glioblastoma. J Cell Mol Med 13:136-146

225. Hu YY et al (2011) Notch signaling contributes to the maintenance of both normal neural stem cells and patient-derived glioma stem cells. BMC Cancer 11:82

226. Kristoffersen K, Villingshoj M, Poulsen HS, Stockhausen MT (2013) Level of Notch activation determines the effect on growth and stem cell-like features in glioblastoma multiforme neurosphere cultures. Cancer Biol Ther 14:625-637

227. Dell'albani P et al (2014) Differential patterns of NOTCH1-4 receptor expression are markers of glioma cell differentiation. Neuro Oncol 16:204-216

228. Gilbert CA, Daou MC, Moser RP, Ross AH (2010) Gammasecretase inhibitors enhance temozolomide treatment of human gliomas by inhibiting neurosphere repopulation and xenograft recurrence. Cancer Res 70:6870-6879

229. Hovinga KE et al (2010) Inhibition of notch signaling in glioblastoma targets cancer stem cells via an endothelial cell intermediate. Stem Cells 28:1019-1029

230. Wang J, Wakeman TP, Lathia JD, Hjelmeland AB, Wang XF, White RR, Rich JN, Sullenger BA (2010) Notch promotes radioresistance of glioma stem cells. Stem Cells 28:17-28

231. Fan X et al (2010) NOTCH pathway blockade depletes CD133positive glioblastoma cells and inhibits growth of tumor neurospheres and xenografts. Stem Cells 28:5-16

232. Taylor IC et al (2015) Disrupting NOTCH slows diffuse intrinsic pontine glioma growth, enhances radiation sensitivity, and shows combinatorial efficacy with bromodomain inhibition. J Neuropathol Exp Neurol 74:778-790

233. Luo D, Wang J, Li J, Post M (2011) Mouse snail is a target gene for HIF. Mol Cancer Res 9:234-245

234. Zhu GH, Huang C, Feng ZZ, Lv XH, Qiu ZJ (2013) Hypoxiainduced snail expression through transcriptional regulation by HIF-1alpha in pancreatic cancer cells. Dig Dis Sci 58:3503-3515

235. Liu $Y$ et al (2014) HIFs enhance the migratory and neoplastic capacities of hepatocellular carcinoma cells by promoting EMT. Tumour Biol 35:8103-8114

236. Lv B et al (2015) CXCR4 signaling induced epithelial-mesenchymal transition by PI3 K/AKT and ERK pathways in glioblastoma. Mol Neurobiol 52:1263-1268

237. Xi Y et al (2013) Identification of pY654-beta-catenin as a critical co-factor in hypoxia-inducible factor-1alpha signaling and tumor responses to hypoxia. Oncogene 32:5048-5057

238. Hardee ME, Zagzag D (2012) Mechanisms of glioma-associated neovascularization. Am J Pathol 181:1126-1141

239. Mahase S, Rattenni RN, Wesseling P, Leenders W, Baldotto C, Jain R, Zagzag D (2017) Hypoxia-mediated mechanisms associated with antiangiogenic treatment resistance in glioblastomas. Am J Pathol 187:940-953

240. Kim SW et al (2015) Genome-wide transcript profiling reveals novel breast cancer-associated intronic sense RNAs. PLoS One 10:e0120296

241. Keith B, Simon MC (2007) Hypoxia inducible factors, stem cells and cancer. Cell 129:465-472

242. Franovic A, Holterman CE, Payette J, Lee S (2009) Human cancers converge at the HIF-2alpha oncogenic axis. Proc Natl Acad Sci USA 106:21306-21311

243. Cho KH, Choi MJ, Jeong KJ, Kim JJ, Hwang MH, Shin SC, Park CG, Lee HY (2014) A ROS/STAT3/HIF-1alpha signaling cascade mediates EGF-induced TWIST1 expression and prostate cancer cell invasion. Prostate 74:528-536

244. Heddleston JM, Li Z, McLendon RE, Hjelmeland AB, Rich JN (2009) The hypoxic microenvironment maintains glioblastoma stem cells and promotes reprogramming towards a cancer stem cell phenotype. Cell Cycle 8:3274-3284

245. McCord AM, Jamal M, Shankavaram UT, Lang FF, Camphausen K, Tofilon PJ (2009) Physiologic oxygen concentration enhances the stem-like properties of CD133+ human glioblastoma cells in vitro. Mol Cancer Res 7:489-497

246. Pistollato F et al (2009) Hypoxia and HIF1alpha repress the differentiative effects of BMPs in high-grade glioma. Stem Cells 27:7-17

247. Li Z et al (2009) Hypoxia-inducible factors regulate tumorigenic capacity of glioma stem cells. Cancer Cell 15:501-513

248. Dong CG, Wu WK, Feng SY, Yu J, Shao JF, He GM (2013) Suppressing the malignant phenotypes of glioma cells by lentiviral delivery of small hairpin RNA targeting hypoxia-inducible factor-1alpha. Int J Clin Exp Pathol 6:2323-2332

249. Mendez O, Zavadil J, Esencay M, Lukyanov Y, Santovasi D, Wang SC, Newcomb EW, Zagzag D (2010) Knock down of 
HIF-1alpha in glioma cells reduces migration in vitro and invasion in vivo and impairs their ability to form tumor spheres. Mol Cancer 9:133

250. Shen SH, Kwan AL, Chen YY, Wang ZX (2013) Effect of silencing HIF-1alpha on proliferation, invasion and migration of glioblastoma U87 cells. Neurol Sci 34:365-371

251. Gillespie DL, Whang K, Ragel BT, Flynn JR, Kelly DA, Jensen RL (2007) Silencing of hypoxia inducible factor-1alpha by RNA interference attenuates human glioma cell growth in vivo. Clin Cancer Res 13:2441-2448

252. Luo $\mathrm{Z}$ et al (2015) Silencing of HIF-1alpha enhances the radiation sensitivity of human glioma growth in vitro and in vivo. Neuropharmacology 89:168-174

253. Khatua $\mathrm{S}$ et al (2003) Overexpression of the EGFR/FKBP12/ HIF-2alpha pathway identified in childhood astrocytomas by angiogenesis gene profiling. Cancer Res 63:1865-1870

254. Appolloni I, Barilari M, Caviglia S, Gambini E, Reisoli E, Malatesta P (2015) A cadherin switch underlies malignancy in highgrade gliomas. Oncogene 34:1991-2002

255. Perez-Moreno M, Fuchs E (2006) Catenins: keeping cells from getting their signals crossed. Dev Cell 11:601-612

256. Perez-Moreno M, Jamora C, Fuchs E (2003) Sticky business: orchestrating cellular signals at adherens junctions. Cell 112:535-548

257. Schmalhofer O, Brabletz S, Brabletz T (2009) E-cadherin, betacatenin, and ZEB1 in malignant progression of cancer. Cancer Metastasis Rev 28:151-166

258. Bienz M (2005) beta-Catenin: a pivot between cell adhesion and Wnt signalling. Curr Biol 15:R64-R67

259. Qian X et al (2014) N-cadherin/FGFR promotes metastasis through epithelial-to-mesenchymal transition and stem/progenitor cell-like properties. Oncogene 33:3411-3421

260. Liang F, Zhang S, Wang B, Qiu J, Wang Y (2014) Overexpression of integrin-linked kinase (ILK) promotes glioma cell invasion and migration and down-regulates E-cadherin via the NFkappaB pathway. J Mol Histol 45:141-151

261. Velpula KK, Rehman AA, Chelluboina B, Dasari VR, Gondi CS, Rao JS, Veeravalli KK (2012) Glioma stem cell invasion through regulation of the interconnected ERK, integrin alpha6 and N-cadherin signaling pathway. Cell Signal 24:2076-2084

262. Zhao C, Li X, Su C, Li J, Cheng N, Ren S, Chen X, Zhou C (2015) High expression of E-cadherin in pleural effusion cells predicts better prognosis in lung adenocarcinoma patients. Int $\mathrm{J}$ Clin Exp Pathol 8:3104-3109

263. Guo Y, Yin J, Zha L, Wang Z (2013) Clinicopathological significance of platelet-derived growth factor B, platelet-derived growth factor receptor-beta, and E-cadherin expression in gastric carcinoma. Contemp Oncol (Pozn) 17:150-155

264. Wu W, Tian Y, Wan H, Song Y, Li J, Zhang L (2013) The expressions of Wnt/beta-catenin pathway-related components in brainstem gliomas. Can J Neurol Sci 40:355-360

265. Wu W, Tian Y, Wan H, Ma J, Song Y, Wang Y, Zhang L (2013) Expression of beta-catenin and $\mathrm{E}$ - and $\mathrm{N}$-cadherin in human brainstem gliomas and clinicopathological correlations. Int J Neurosci 123:318-323

266. Lewis-Tuffin LJ, Rodriguez F, Giannini C, Scheithauer B, Necela BM, Sarkaria JN, Anastasiadis PZ (2010) Misregulated E-cadherin expression associated with an aggressive brain tumor phenotype. PLoS One 5:e13665

267. Harris LW, Lockstone HE, Khaitovich P, Weickert CS, Webster MJ, Bahn S (2009) Gene expression in the prefrontal cortex during adolescence: implications for the onset of schizophrenia. BMC Med Genom 2:28

268. Reifenberger $\mathrm{G}$ et al (2014) Molecular characterization of longterm survivors of glioblastoma using genome- and transcriptome-wide profiling. Int J Cancer 135:1822-1831

269. Mohedas AH et al (2014) Structure-activity relationship of 3,5-diaryl-2-aminopyridine ALK2 inhibitors reveals unaltered binding affinity for fibrodysplasia ossificans progressiva causing mutants. J Med Chem 57:7900-7915

270. Funato K, Major T, Lewis PW, Allis CD, Tabar V (2014) Use of human embryonic stem cells to model pediatric gliomas with H3.3K27 M histone mutation. Science 346:1529-1533

271. Lewis PW et al (2013) Inhibition of PRC2 activity by a gain-offunction $\mathrm{H} 3$ mutation found in pediatric glioblastoma. Science 340:857-861

272. Justin N et al (2016) Structural basis of oncogenic histone H3K27 M inhibition of human polycomb repressive complex 2. Nat Commun 7:11316

273. Nagaraja $S$ et al (2017) Transcriptional dependencies in diffuse intrinsic pontine glioma. Cancer Cell 31(635-652):e6 